\title{
Teaching electric circuits with a focus on potential differences
}

\author{
Jan-Philipp Burde $\odot^{*}$ \\ University of Tübingen, Department of Physics Education Research, \\ Auf der Morgenstelle 14, 72076 Tübingen, Germany \\ Thomas Wilhelm (1) \\ Goethe University, Department of Physics Education Research, \\ Max-von-Laue-Str.1, 60438 Frankfurt am Main, Germany
}

(Received 7 July 2019; accepted 19 December 2019; published 4 December 2020)

\begin{abstract}
[This paper is part of the Focused Collection on Curriculum Development: Theory into Design.] Developing a solid understanding of simple electric circuits represents a major challenge to most students in middle school. In particular, students tend to reason exclusively with current and resistance when analyzing electric circuits as they view voltage as a property of the electric current and not an independent physical quantity. As a result, they often struggle to understand the important relationship between voltage and current in electric circuits. Following diSessa's interpretation of learning as the construction and reorganization of previously loosely connected elements of knowledge ("p-prims") into a coherent mental structure ("coordination class"), a new curriculum was developed that systematically builds on students' everyday experiences with air pressure (e.g., with air mattresses and bicycle tires). In order to make voltage rather than current the students' primary concept when analyzing electric circuits, voltage is introduced as an "electric pressure difference" across a resistor that is as much the cause for an electric current as air pressure differences are the cause for air flow. The objective of the curriculum is to provide a structure for students to develop a qualitative understanding of simple dc circuits that allows them to make intuitive inferences about the electric current based on voltage and resistance. With an effect size of $d=0.94$ the new curriculum has proven to be more effective than traditional approaches for teaching electric circuits in a quasi-experimental field study with 790 students from Frankfurt am Main, Germany.
\end{abstract}

DOI: 10.1103/PhysRevPhysEducRes.16.020153

\section{INTRODUCTION}

Few discoveries have had such an impact on our civilization as the discovery of electricity. Despite its cultural and technological importance, most students have only a very vague understanding of its core quantities such as voltage, resistance, and current and their mutual relationship in simple circuits when they leave middle school [1-3]. As a result of these findings, a lot of research was conducted on students' learning difficulties in the field of introductory electricity over the past decades [4]. These research findings suggest that so-called simple electric circuits are in fact, from a learner's perspective, not simple at all but represent a major challenge for many students [5]. Considering that the concepts involved are quite complex and that the physical processes such as the movement of

\footnotetext{
*Jan-Philipp.Burde@uni-tuebingen.de

Published by the American Physical Society under the terms of the Creative Commons Attribution 4.0 International license. Further distribution of this work must maintain attribution to the author(s) and the published article's title, journal citation, and DOI.
}

electrons elude direct perception, these research findings might not be surprising. However, research has also shown that students often still lack a basic qualitative understanding of simple electric circuits even after years of physics teaching [6,7]. As students' understanding of simple circuits often remains fragmentary even after instruction, it was proposed that teaching at the secondary level should focus more on a conceptual understanding of circuits and less on a quantitative circuit analysis [8].

The lack of qualitative understanding is particularly apparent when the mathematical introduction of Ohm's law precedes a qualitative understanding of its underlying physical quantities. Students then struggle to attribute meaning to the concepts of the formula $V=I R$, often resorting to algorithmic manipulations of Ohm's law without having a conceptual understanding of the relationship it displays $[6,9]$. Even if considerable time is dedicated to developing a qualitative understanding of electric circuits, students often struggle to develop an adequate conceptual understanding of voltage [10]. In particular, research in physics education has shown that voltage is often regarded by students as a property or component of the electric current and not as an independent physical quantity [5-7,11,12]. 
This is not only a problem because voltage is then not understood as a potential difference, but more importantly because students then fail to understand the central relationship between voltage and current [6]. As a result, the electric current dominates students' thinking about electric circuits at the expense of potential differences as they try to analyze circuits exclusively from the perspective of the flow of current $[6,11]$. Furthermore, students often think that a battery supplies an electric circuit with a constant current not realizing it maintains a constant potential difference across its terminals [6]. A recent study by Smith and van Kampen [13] showed that even preservice science teachers consider the battery a source of constant current and analyze circuits based on the concepts of current and resistance often completely ignoring potential differences in their reasoning.

Since a robust conceptual understanding of voltage as a potential difference is key to effective analysis of electric circuits, the ill-founded focus on the concept of current in traditional teaching unnecessarily prevents a deeper understanding. In particular, such an approach may trigger students to put themselves in the role of the electric current that "travels" around the circuit element by element [1]. It is easy to conceive that such an understanding of circuits forms the basis of what is often referred to as "sequential reasoning" and "local reasoning" (e.g., examining the circuit in terms of "before and after" a current has flowed through a component or focusing only on one point in a circuit while ignoring the relation to the rest of the circuit) $[5,14]$. As this topic is a part of the core curriculum, the perceived failure to develop an understanding for "simple" electric circuits can negatively affect any high school student. This perceived failure is particularly problematic from a gender perspective, given that girls often tend to attribute their lack of understanding to their own inability or lack of "talent" for physics $[15,16]$. This situates developing a research-based curriculum that effectively addresses these problems and supports the development of an adequate conceptual understanding of electric circuits as a meaningful endeavor for physics education researchers.

\section{TRADITIONAL APPROACHES}

As a first step, it is necessary to take a closer look at traditional approaches to teaching electricity in order to identify potential factors that prevent students from developing an adequate conceptual understanding of circuits. In a detailed analysis of how electric circuits were historically covered in textbooks, Guisasola [8] points out that one cause for students' learning difficulties regarding the electric potential in circuits may lie in the way electrostatics and electric circuits are traditionally presented. While the concepts of electric charge, electric field, and electric potential play an important role in chapters on electrostatics, these concepts are rarely even mentioned in chapters on simple circuits [17-19]. As these chapters focus instead on directly observable or measurable quantities such as current and resistance, the danger is that students think of circuits and electrostatics as two completely unrelated topics [20]. In particular, it is argued that students might not realize the important role that the electric potential plays in circuits. As pointed out by Härtel [21], students' understanding of the role of potential differences in electric circuits is made even more difficult by the fact that the concept of potential is usually introduced only mathematically without attempting to provide students with a conceptual understanding of the relationship between potential differences and current. Furthermore, there seems to be a lack of consensus among researchers on the question of which concepts should be at the center of a curriculum on circuits [8]. While some believe the electric current should be the main concept [3], others are convinced that the focus should be on potential differences [22,23].

A powerful alternative to explaining electric circuits either based on the concept of current or on voltage is proposed by Chabay and Sherwood in a textbook aimed at university students [24]. In order to provide students with a better understanding of the relationship between macroscopic phenomena (e.g., voltage across resistors) and their explanations at a microscopic level, the textbook focuses on the role of surface charges in electric circuits. By illustrating how a change in the density of surface charges generates an electric field (and thus a voltage) that drives the current through the circuit, Chabay and Sherwood [24] provide students with a conceptual understanding of circuits that is based on concepts from electrostatics. The traditional separation between micro- and macrolevel models of electric circuits is also criticized by Sengupta and Wilensky [25] from the knowledge-in-pieces perspective [26]. They argue that "misconceptions in the domain of electricity could be understood as evidence of "slippage between [the two] levels" "as students inappropriately apply object-based thinking at an individual level (e.g., flow) to emerging phenomena at an aggregate level (e.g., the electric current). However, instead of ignoring students' intuitive thinking, they propose an instructional design that builds on students' repertoire of productive knowledge elements at a microlevel in order to allow them a deeper understanding of the aggregate-level relationship between current, voltage, and resistance. Empirical results suggest that this emergent approach, which also brings together electrostatics and circuits, can support undergraduate students to develop a better understanding of the relevant phenomena in circuits [25]. As pointed out by Guisasola [8], however, "textbooks avoid a presentation that relates micro and macro views, possibly because surface densities of charge, small in normal dc and ac circuits, are difficult to measure in the laboratory." A more detailed analysis of the relations between macroscopic level observations and microscopic level theories in electric circuits and the historic development of the role of 
surface charges in textbooks on electric circuits can be found in Guisasola [8].

In the German speaking world, the introduction to electricity in lower secondary schools was historically primarily based on electrostatics and electric potential (cf. Ref. [27]). However, at the beginning of the 20th century, the focus shifted towards electric current, which subsequently dominated teaching at the expense of potential and potential difference [28]. Based on the research into students' alternative conceptions in the 1980s, the hypothesis was put forward that the focus on current prevents students from developing an understanding for the important relationship between voltage and current $[6,11]$. By studying the rather concrete and intuitive concept of electric current at length before discussing the role of potential differences in electric circuits, students may no longer see the need for voltage as an additional and rather abstract quantity when analyzing electric circuits. Criticizing the emphasis on current rather than potential difference in traditional approaches to teaching electric circuits, Cohen, Eylon, and Ganiel argue that "first impressions are strong and may impede a later, more rigorous, study of electricity" as most students consider current the primary concept when analyzing circuits even after instruction [6]. In order to help students understand the important role that potential differences play in electric circuits, Cohen, Eylon, and Ganiel call for a curriculum that not only "[...] clearly spells out the relation of cause and effect between pd [potential difference] and current," but also introduces the concept of potential difference first [6]. For this purpose, they propose an analogy in which the battery exerts a "pressure" on the charges in the wire, "pushing" it through a light bulb.

Another major impediment for the development of an adequate conceptual understanding of voltage at lower secondary school level is seen in the examples that are typically discussed in class. The main criticism is that traditional teaching often exclusively focuses on situations where voltage and current occur simultaneously, i.e., in closed circuits. The exclusive analysis of such examples using the equation $V=I R$ is particularly problematic as it may seem to suggest that voltage requires an electric current. More specifically, there is a danger that such an analysis of circuits may lead students to think of voltage as a property of the electric current, since voltage and current are always proportional to each other [29,30]. As a result, students do not realize that even when there is no current in an open circuit, a voltage can still be present [31].

Another decisive factor for a deeper understanding of the relationship between voltage and current is the way voltage is introduced. As a potential difference, voltage always refers to two points in a circuit and is therefore often considered to be more difficult to understand than the electric potential that refers to a single point [32]. However, the concept of electric potential is rarely covered in German textbooks for lower secondary schools. Instead, voltage is often introduced as "energy per charge" or simply as "the cause of current flow" without any reference to electric potential or potential differences. Although such an introduction of the concept of voltage is not wrong in itself, it is unsuitable to qualitatively explain the mutual relationship between voltage and current. Similarly, this manner of explanation is unsuitable for building the understanding that there exists a voltage between two distinct points of an open circuit [33]. An adequate understanding of voltage, and, in particular, its relative character, appears possible only if students are familiar with its underlying quantity, namely, the electric potential.

A teaching approach for secondary schools that not only uses voltage as the primary concept when introducing students to simple electric circuits, but also emphasizes that voltage refers to two points, was developed by Psillos, Tiberghien, and Koumara [22]. As students often find it difficult to understand that voltage can only exist between two points, the curriculum introduces voltage by first measuring it between the terminals of a battery. This contrasts with other curricula that usually start with an introduction of the electric current (e.g., Ref. [3]). Next, a voltmeter is connected in series with a battery and a bulb to demonstrate to students that voltage can be present without current. In subsequent units it is then discussed, for example, that the voltage of a battery does not depend on its size, but whether the batteries are connected in series or in parallel. Considering students' learning difficulties with the concept of voltage, the curriculum by Psillos, Tiberghien, and Koumaras [22] represents a step in the right direction. However, voltage is only introduced as a property of a battery that is the result of charge separation across its terminals. The voltage distribution within a circuit, for example, across resistors, is not addressed at all. In addition, the curriculum only suggests the order in which the physical quantities should be introduced. As mentioned at the beginning, a major obstacle to a better understanding of circuits is also the abstract nature of the concepts involved. The proposed curriculum can therefore be criticized for not taking into account students' everyday experiences in order to facilitate an intuitive understanding of circuit behavior, e.g., by using an appropriate analogy.

At the university level, the approach taken by Chabay and Sherwood [24] can be seen as a big step forward as it provides students with microscopic explanations (e.g., surface charges) for macroscopic phenomena (e.g., voltage across resistors) and thereby unifies electrostatics and dc circuits. However, the authors of this paper believe that an analysis of electric circuits based on a gradient of surface charges that cause an electric field in the wire is too abstract for secondary school students. Nonetheless, a first introduction to the topic should focus on providing students with a qualitative understanding of circuit behavior. Since it is generally agreed that an adequate conceptual 
understanding of circuits requires a robust concept of voltage, providing students with the opportunity to develop a qualitative understanding of voltage as a potential difference should be at the center of an effective curriculum of electric circuits [34]. In particular, such a curriculum should give meaning to the concept of potential difference as the cause of the electric current in simple electric circuits $[6,21]$.

\section{ANALOGIES OF ELECTRIC CIRCUITS}

Analogies are not only ubiquitous in scientific practice, but also play a central role in science teaching and learning [35]. In the history of physics, for example, Ohm derived the laws about flowing electricity via an analogy to heat conduction [36]. In science education, research has shown that the use of analogies can have a positive influence on students' learning outcomes [37]. Considering that the physical processes in circuits like the electron movement are beyond direct perception and hence hard to imagine for students, teachers often use models and analogies to make the topic more accessible. In particular, the idea is to make it easier for students to understand abstract concepts by comparing them to phenomena students can relate to from previous experience. Using the terminology of the influential structure mapping theory (SMT) by Gentner, analogies foster understanding by mapping objects and relations in the source domain onto similar ones in the target domain [38]. More specifically, the kind of analogical reasoning described here is drawing inferences about a not well understood target domain based on a well understood source domain. This, however, is only possible if both domains share a common structure in both objects and relation. An effective analogy is characterized by the fact that students' intuition from the source domain successfully "operates" in the target domain [39].

However, the use of analogies in teaching is not entirely unproblematic, which is why analogies have been described as "two edged swords" [40]. On the one hand instructional analogies can be "bridges to understanding," but on the other hand they can also provoke learning difficulties if students do not have an adequate understanding of the source domain. The identification of phenomena and situations that can serve as the source domain of an analogy is therefore an important task for curriculum designers. A recent study by Kapon and diSessa examined the role of differences in students' prior knowledge in relation to their ability to make inferences about the target domain when they have to reason through the same instructional analogy. A key finding of the study is that students' prior knowledge, in the form of intuitive knowledge elements, as well as the "[...] judged applicability [of these intuitive knowledge elements by the learner] to the target" plays an important role whether "[...] the source and target [are accepted by the learner] as essentially similar in ways the instructional analogy intended to portray" [41].
From a knowledge in pieces (KiP) perspective on learning, as described in more detail below, it is therefore particularly important that the source evokes intuitive knowledge elements that not only operate well in the target domain, but are also judged by the learners to apply to the target domain. The instructional strategy should then be to allow students to make a seamless transition from their intuitive understanding to a scientific understanding based on the corresponding analogy. Owing to these considerations, the following sections review two analogies of the electric circuit and examine as to whether we can expect students to benefit from them given their prior knowledge in the corresponding source domains.

A particularly widespread analogy when teaching circuits is the water circuit analogy with horizontal water flow in water pipes with a given width. In this analogy, the electric potential corresponds to the water pressure inside the water pipes [42]. Voltage as a potential difference hence corresponds to a water pressure difference between two points in the circuit. Since this water pressure difference is caused by a water pump, the force of gravity can be ignored. Although this analogy is quite powerful from a physical perspective, it has proven to be less effective than generally expected, possibly because students have no previous experience with water pressure in water pipes [43]. Since water under high pressure differs neither visibly nor tangibly from water under low pressure, many students consider water to be an incompressible fluid and lack a conceptual understanding for water pressure. Without an understanding of the source domain, students often fail to grasp the core of the analogy, namely, that water pressure differences are the cause of water flow. Moreover, it has been shown that students face similar difficulties understanding other key concepts behind the water circuit analogy to those they face understanding the electric circuit, for example, that the rate of flow is the same everywhere in the water circuit [43].

In other ways, however, the introduction of voltage as a potential difference has proven to be comparatively effective in fostering a better conceptual understanding of circuits in a number of studies [28,44,45]. An analogy that introduces voltage as a potential difference, but that is more compelling to learners than the water circuit analogy, is the air pressure analogy employed in the CASTLE curriculum [46]. A big advantage of this analogy over the water analogy is that students come to class with an adequate conceptual understanding of the source domain, given the readily apparent compressibility of air [34]. Based on their concrete experiences with everyday objects such as air mattresses or bicycle tires, students develop an intuitive understanding of air pressure. By comparing air pressure differences to potential differences in circuits, the air pressure analogy thus represents a promising way to illustrate the relationship between potential difference and current to students in middle school. 


\section{MOTIVATION FOR RESEARCH}

While the CASTLE curriculum with its compelling air pressure analogy certainly represents a step in the right direction, a number of shortcomings pertaining to its design and empirical evaluation can be identified. In contrast to the considerations made by Cohen et al. [6], for example, the first concept introduced in the CASTLE curriculum is the electric current [44]. Although much emphasis is placed in later chapters on the important role that potential differences play in circuits, this traditional content structure of the CASTLE curriculum may unnecessarily hamper the development of a robust understanding of the relationship between voltage and current as discussed above. From a methodological point of view, the CASTLE curriculum places great value on hands-on experiments with specially designed capacitors with very large capacitances. Unfortunately, a widespread adoption of this approach into the curriculum in German schools is unfeasible for at least three reasons. First, the necessary capacitors are usually not available in sufficient numbers in schools. Second, the usual 45-min length of a lesson in Germany is not well suited for a curriculum based primarily on time-consuming hands-on experiments. Third, a curriculum with a focus on capacitors would probably not be accepted by German physics teachers in the first place, as capacitors are not part of the curriculum in lower secondary schools in Germany. Furthermore, despite claims that the CASTLE curriculum leads to significantly larger achievement gains than traditional approaches [44], detailed results of an empirical evaluation have never been published.

Owing to these considerations, a design-based research (DBR) project was set up in Frankfurt, Germany in order to develop a curriculum that utilizes the compelling air pressure analogy, introduces potential difference before current and requires no additional equipment to implement. With its focus on a qualitative understanding of electric circuits, the curriculum presented in this paper is aimed at students in middle schools with no necessary prior knowledge of electric circuits. Building on diSessa's perspective on learning [26], the new curriculum aims to support students to develop a qualitative conceptual understanding of electric circuits that has its origins in everyday physical intuitions with air pressure. In line with the demands of Cohen et al. [6], a key objective of the new curriculum is to make voltage rather than current the students' primary concept when analyzing electric circuits. The new curriculum, in particular, strives to help students understand that potential differences are as much the cause for an electric current as air pressure differences are the cause for air flow. As the electric potential is traditionally only introduced mathematically, the air pressure analogy is used here to give meaning to the concept of potential difference $[21,44]$. By illustrating to students that a piece of fabric impedes an air flow, the curriculum furthermore aims to provide students with a first qualitative idea of electric resistance.
The curriculum then focuses on simple parallel and series circuits in order to support students in developing a qualitative understanding of the mutual relationship between $V, R$, and $I$. At the end of the curriculum, this qualitative understanding then forms the basis for a quantitative understanding of Ohm's law in simple dc circuits. A detailed list of the learning outcomes students are expected to achieve after each unit of the curriculum can be found in Ref. [47].

The focus of this paper lies on the question how theoretical considerations based on the KiP perspective have shaped the design of the curriculum. In particular, it is discussed how the specific design of the curriculum was guided by the basic assumptions and concepts of the KiP perspective on learning. For example, the curriculum systematically aims to identify and build on students' productive knowledge elements (p-prims) based on the assumption of KiP that these naïve ideas can represent positive learning resources, even if these ideas are from a different domain ("domain flexibility"). A major advantage of the KiP perspective is that it provides curriculum designers with a framework for describing the structure of scientific concepts in the form of coordination classes. Using this framework, the curriculum first aims to support students in identifying potential differences in circuits ("extraction") before addressing the question how potential difference and resistance affect the electric current ("inferential net").

However, even though the curriculum was significantly shaped by the KiP perspective, the purpose of this paper is not to contribute to the theory of KiP itself. This paper is therefore not primarily concerned with the underlying complexity in students' thinking about electric circuits and which knowledge pieces might be involved at any point in the curriculum. Although students certainly come to class with a range of many different and overlapping intuitions considering their different backgrounds and prior experiences, this paper does not aim to provide a detailed analysis of the students' conceptual ecologies. In particular, the objective is not to investigate the thinking of individual students, e.g., in interview settings (cf. Ref. [48]). Instead, the purpose of our study was to find out whether the curriculum presented in this paper and developed through the theoretical lens of KiP leads to a better conceptual understanding than traditional approaches to teaching electric circuits if widely adopted in schools in Germany. As part of the DBR project, the new curriculum was therefore empirically evaluated with 790 students using a two-tier multiple-choice test. Furthermore, the teachers who had taught according to the new curriculum were asked to give feedback on their experiences with it in order to get information on its strengths and weaknesses from the practitioners' point of view. The empirical evaluation of the curriculum is discussed in more detail at the end of this paper. 
As it is common for design-based research with its dedication to continual improvement, however, we first conducted a series of one-on-one interviews with students on a draft version of the curriculum using the technique of probing acceptance (cf. Ref. [49]). This technique was introduced over 25 years ago [50] to get an "[...] insight into the plausibility of an information input in terms of whether it makes sense to students. Probing acceptance thus means identifying elements of the instruction that students accept as useful and meaningful information [...]" [49]. As part of these one-on-one interviews, students were first introduced to key concepts of the curriculum and were then asked to evaluate and paraphrase them. The aim here was to get an insight into the different intuitive ideas that might be activated when students engage with the curriculum. Furthermore, students were asked to apply these ideas to new situations in order to identify learning difficulties at an early stage. In the present study, these one-on-one interviews, each lasting about two hours, were conducted with nine sixth-grade students who had no significant prior knowledge of electric circuits. As this paper focuses on how the design of the curriculum was shaped by the theory of KiP, the findings of these interviews and their impact on the curriculum can only be briefly discussed in order to illustrate that the complexity in students' thinking were not overlooked in its development. A more detailed description of how the design of the curriculum presented in this paper was influenced by these interviews can be found in Refs. [47,51].

\section{DESIGN-BASED RESEARCH}

As mentioned before, the curriculum presented in this paper was developed as part of a design-based research project. Design-based research (DBR) is a paradigm that aims to refine both theory and practice by systematically developing and studying learning environments in authentic settings in order to contribute to sustained innovation in education [52-54]. Although laboratory experiments and large-scale studies are certainly valuable for educational research, these traditional methodologies have been criticized for not contributing to "usable knowledge" [55,56]. The main point of criticism is that these approaches often fail to support sustained innovation in education as they primarily evaluate the status quo by testing scientific hypotheses [54,57]. In particular, laboratory experiments aimed at controlling as many variables as possible have been criticized for studying artificial situations that have little to do with the complexities of real-life learning [53]. As a result, such experiments produce scientific knowledge that has little impact on teaching and learning [56].

In contrast, design-based research, which is largely attributed to Ann Brown [55] and Allan Collins [58], strives to develop effective learning environments and is conducted in authentic learning settings such as classrooms. Considering such settings as natural laboratories,
DBR aims to systematically evaluate the effectiveness of educational designs while simultaneously pursuing the goal of developing and advancing domain specific theories of learning and teaching that transcend the local context in which they were generated (see Sec. VIII) [52]. In other words, rather than only testing existing theories, DBR pursues the dual goals of meaningfully impacting educational practice as well as improving the theoretical knowledge of the field [57]. In contrast to grand educational theories such as constructivism, however, DBR has the objective to generate knowledge that informs prospective design and is relevant for educational researchers and practitioners alike [59].

The design of a new learning environment often aims to solve a current educational problem and draws on theoretical considerations and previous research findings. In less wellresearched areas, however, it may be necessary to first conduct pilot work, e.g., by conducting one-on-one interviews with students to identify their domain specific intuitive ideas and learning difficulties. A defining characteristic of design-based research is its iterative character as DBR projects often include multiple cycles of design, intervention, and redesign $[58,59]$. Since the design is constantly revised and improved based on the findings of each cycle, DBR represents a formative research methodology. Consequently, design-based research projects usually require a close cooperation between educational researchers and practitioners in schools that share a long-term vision and commitment to continual improvement.

Since DBR projects usually take place in settings where many variables cannot be controlled, researchers often try to triangulate quantitative and qualitative data from a variety of sources [60]. In the present study, for example, a quantitative multiple-choice test was used to evaluate students' conceptual understanding (see Sec. IX B) while qualitative interviews were conducted to investigate students' prior knowledge (see Sec. VII) and the teachers' experiences with the curriculum (see Sec. IX D). However, it is not the methods that define DBR, but its dedication to sustained innovation in education and "a research community driven by potentiality" [54].

\section{KNOWLEDGE IN PIECES}

Today, practitioners and educational researchers generally agree that students' prior knowledge plays a crucial role in learning physics. However, since the late 1980s, there has been an ongoing debate about the epistemological nature of this pre-instructional knowledge, which has proven to be highly resistant to change [61,62]. Based on the observation that students harbor a series of seemingly stable "misconceptions" in the domain of physics, it was hypothesized that students come to class with a small number of coherent and stable, but naïve knowledge structures [63,64]. These knowledge structures that students develop unconsciously based on their daily experiences are considered by some to be 
theorylike. Early proponents of this perspective even suggested that students' naïve "theories" were comparable to scientific theories such as the impetus theory before Newton [65]. Although it is generally agreed today that students are not explicitly aware of their naive theories, it is assumed that these unconscious but stable mental structures nevertheless form a coherent explanatory framework that determines students' thinking and interpretation of the physical world. As a result of the assumed coherence of students' naïve ideas, proponents of this perspective such as Vosniadou are convinced that a scientific concept can only be introduced to students if their whole "framework theory" is restructured [63]. An important consequence of this view is that students' pre-instructional knowledge is not seen as a resource for learning, but as an obstacle since it is assumed to be incommensurable with the scientifically accepted concepts. Consequently, "bridging the gap" between the students' old ways of thinking and the scientific view is not seen as a viable option.

A fundamentally different view on the nature of preinstructional knowledge was proposed by diSessa with his "knowledge in pieces" perspective [61]. According to this view, students' naïve understanding of physics cannot be considered as theorylike. Instead, it is assumed that students' " $[\ldots]$ naïve physical intuition consists of a large number of nearly independent, small grain size elements, called p-prims [48]. These "p-prims" or "phenomenological primitives" represent minimal abstractions from everyday experience such as "speed is proportional to force" or "increased effort begets greater results" [66]. As such, they could also be described as a large pool of "little intuitions" that enables people to make sense of the physical world. Since p-prims cannot be interpreted as universal claims, it is unilluminating to think of them in terms of "true" or "false." Instead, "p-prims produce commonsensical (and correct) results when bound to certain features of the world and 'misconceptions' when bound to others" [48]. In the quote, diSessa touches on two important aspects of the KiP perspective: First, contextuality is an important factor as it is assumed that the activation priority of a p-prim is largely context dependent. Second, p-prims represent "subconceptual" knowledge elements with a smaller "grain size" than traditional concepts. In other words, concepts are viewed as complex systems that are built from a series of fragmented p-prims. The main difference between scientific concepts and "misconceptions," in this perspective, is seen in the stability and (highly situation specific) activation priority of their underlying p-prims. In the KiP perspective, the learning of scientific concepts is understood as the construction, transformation and reorganization of previously only loosely connected p-prims into a more coherent mental structure called "coordination class" [67]. Subsequently, naïve ideas are not seen as counterproductive to learning, but on the contrary, as positive resources that are essential in scaffolding learning, as summed up by diSessa: "Students have a richness of conceptual resources to draw on. Attend to their ideas and help them build on the best of them" [67]. This profoundly constructivist perspective on learning has great implications for curriculum designers. Their task, in the KiP perspective, is to identify productive p-prims and to develop curricula that systematically direct students' reasoning towards a scientific understanding, e.g., by combining and modifying their intuitive ideas in the form of $\mathrm{p}$ prims into a coordination class [48].

In contrast to p-prims, which are fragmented and independent knowledge elements, coordination classes constitute scientific concepts in the KiP perspective. They are described as "a class of concepts that [...] is important in science learning" as they allow people to "see" scientific concepts in the world [67]. In this perspective, the core function of scientific concepts does not lie in determining class membership (e.g., whether a certain animal is a bird or not), but to reliably determine a particular class of information relating to a physical quantity across a wide range of situations (e.g., determining the force on an object). As scientific concepts such as "force," for example, cannot directly be observed, getting the necessary information about them represents a highly complex cognitive task. First, the concept's parameters (e.g., mass and acceleration) need to not only be reliably determined within a certain situation, but also across a wide range of very phenomenologically different situations. This functional component of a coordination class is referred to as "extraction." Second, based on observed parameters correct inferences need to be made in order to determine a scientific concept (e.g., a force depends on the acceleration and mass of an object). This second component of a coordination class is called the "inferential net" and plays a pivotal role in learning scientific concepts [67]. Although an equation such as $F=m a$ may represent an important part of an expert's inferential net, diSessa and Sherin [68] explicitly point out that "qualitative interpretations of equations are more important than precise calculation in equations' role in coordination."

Drawing all this together: A major advantage of the KiP perspective to describe scientific concepts is that it does not only provide a clear description of the function of scientific concepts as coordination classes, but also their underlying structure. Explaining that "seeing in different situations" can constitute the core function of concepts (coordination classes)" and that "shifting the means of seeing [...] is the core problem of conceptual change," diSessa and Sherin point out the important role that perception plays in developing a scientific concept [68]. Proposing that coordination classes consist of a perceptual (extraction) and an inferential component (inferential net), the KiP perspective also offers a more precise notion of the structure of scientific concepts. Based on the idea that p-prims interact with each other to form "concepts," the 
KiP perspective furthermore provides an explanation of how concepts emerge from "subconceptual" knowledge elements. While students' naïve ideas are usually unstable due to the high context sensitivity and the fragmented nature of their underlying p-prims, coordination classes as scientific concepts represent stable mental structures.

The curriculum presented in this paper aims to help students develop a qualitative understanding of how electric current, e.g., through resistors in simple dc circuits, is dependent on voltage and resistance $(I=V / R)$. As pointed out by diSessa, Sherin, and Levin [67], "expertise always involves families of concepts, [which is why] coordination classes typically come in clusters that interact with each other [...]. Thus, they are systems (as opposed to elements, like p-prims) that are nested in higher-level systems (more akin to 'theories')." Following diSessa's interpretation of force $F=m a$ as a coordination class that is itself based on the relation among the coordination classes "mass" and "acceleration" [67,69], we believe that Ohm's law in the form $I=V / R$, e.g., when working out the current through resistors in simple dc circuits, represents a coordination class based on the concepts of "voltage" and "resistance," which may in turn be coordination classes themselves. The interpretation of Ohm's law as a coordination class becomes clear at the example of a simple dc circuit with a battery and a resistor. In order to work out the current through that resistor, students must first "extract" the voltage across the resistor as well as its resistance and then use their inferential net in the form $I=V / R$ to determine the current flowing through it. The curriculum therefore not only systematically addresses the perceptual and inferential components of the described coordination class one after the other, but the curriculum also aims to support students in repurposing and reorganizing their fragmented p-prims into a more stable mental structure.

Although we anticipate that students will generate vast varieties of ideas when engaging with our curriculum, we deliberately focus on those ideas that can act as productive resources for learning and ways to systematically activate these knowledge elements using appropriate cues in the following sections. Similarly, although we do not expect a single set of extractions or inferences when students deal with certain tasks and circuit diagrams, we focus on those that direct students' reasoning towards a scientific understanding. This is in line with diSessa, who sees the task of curriculum designers in developing curricula that systematically direct students' reasoning towards a scientific understanding by identifying and using productive and intuitive knowledge elements [48].

\section{THE NEW CURRICULUM}

\section{A. Air pressure differences as cause of an airflow}

Although the one-on-one interviews conducted on a draft version of the curriculum suggest that most students come to class with an intuitive understanding of air pressure, some students seemed to have little prior experience in this area. Furthermore, it was found that students find it difficult to distinguish between air pressure and air pressure difference. Considering that it is essential to be able to distinguish between these two concepts in order to understand voltage as an "electric pressure difference," we found it necessary that the introduction to the topic of "simple circuits" takes place through an exploration of air pressure phenomena in order to account for the range of students' different prior experiences in this field. The interviews also showed that some students had no intuitive understanding for the role of resistors in electric circuits. In order to account for these difficulties, this introductory unit aims to provide students with a first qualitative idea of electric resistance by illustrating to students that a piece of fabric impedes an air flow.

Based on the constructivist view of learning and particularly on diSessa's KiP perspective, the curriculum builds on students' everyday physical intuitions with air pressure. It is important to point out that this intuitive understanding of air pressure does not correspond to the refined physical scalar concept of pressure as a state variable, but to the everyday experience that compressed air is "under pressure" and tries to push itself out of a container (e.g., an air mattress). Given that "there is no common lexicon for p-prims" [70], we believe that this is an intuitive everyday experience similar to the "vacuum impels" p-prim described by diSessa [66]. Following a short and optional unit on the basics of electrostatics, a series of hands-on experiments with everyday objects such as syringes as mini air pumps or bicycle tires are conducted in order to ensure that all students can gain practical experience with air pressure. Using the example of these experiments, it is then discussed that air always flows from areas of high pressure to areas of low pressure and that pressure differences are the cause for an air flow as shown in Fig. 1. In this context, particular emphasis is placed on the distinction between pressure and pressure differences, as students often tend not to differentiate adequately between these two concepts (see Fig. 3). By initially visualizing air pressure using a particle model, the aim is to make the relationship between compression (the property) and pressure (the state) clearer to the students. The first unit concludes with an introduction to the idea of resistance, in which the students take a piece of fabric (e.g., a scarf, collar, or sleeve) and blow air through it. The thicker the piece of fabric is folded over itself, the stronger the obstruction of the air flow. This obstruction of the air flow by fabric is then referred to as resistance to help students develop a first qualitative idea of electric resistance.

By combining the previously isolated naïve conceptual understanding of air pressure with the two observations that "a pressure difference leads to an air flow" and "a piece of fabric impedes an air flow," the curriculum aims to connect this intuitive knowledge with Ohm's p-prim. According to 


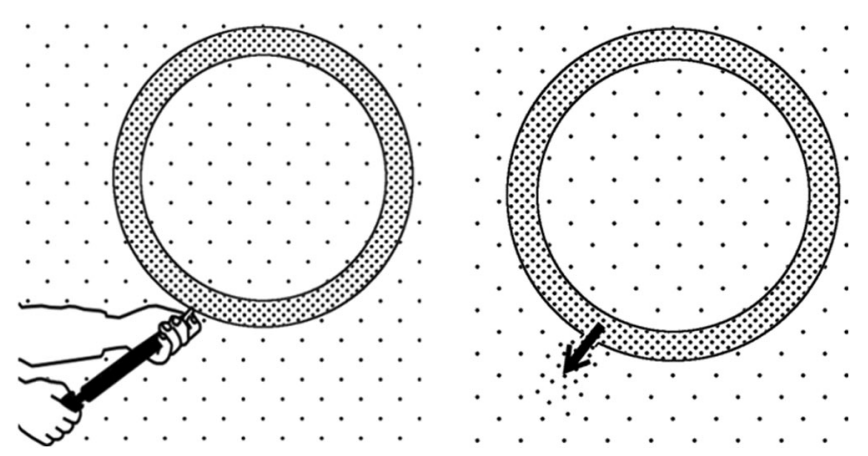

FIG. 1. The example of an inflated bicycle tire is used to illustrate that a pressure difference leads to an air flow using a particle model.

diSessa [61], Ohm's p-prim represents "one of the most fundamental and pervasive p-prims" as it is based on the common experience that "increased effort [...] leads to more result [and] increased resistance leads to less result." [66]. In order to help students apply this p-prim productively to air pressure examples, the qualitative relationship between the air pressure difference, resistance, and airflow is summarized visually in the form of a diagram as shown in Fig. 2 and discussed at further examples. By using the symbols of Ohm's law in the diagram and qualitatively discussing the relationship between the different physical quantities, the aim of this unit is to set the basis for an appropriate inferential net for electric circuits.

\section{An example from the curriculum}

At the beginning of the curriculum, students work on a task that aims to help them to distinguish between air pressure and air pressure differences. The task, which refers to Fig. 3, is as follows:

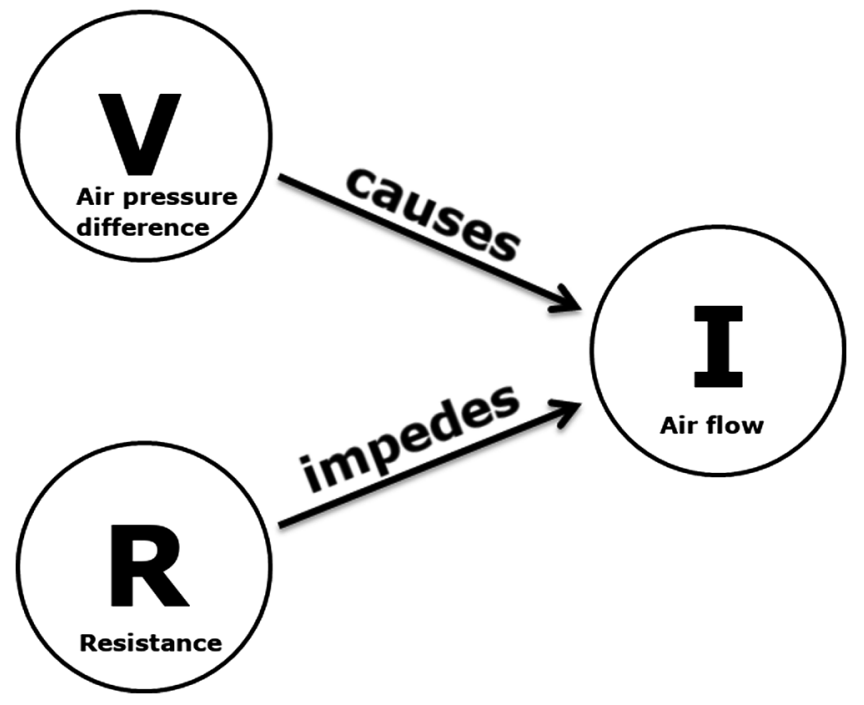

FIG. 2. A simple diagram visualizes the qualitative relationship between air pressure difference, resistance, and air flow.
Look at the three closed pipes in Fig. 3. The air pressure is different in each of the pipes.

(a) Color the areas with high air pressure in red and areas with low air pressure in blue and areas with normal pressure in yellow.

(b) What is the pressure difference between the following points? Answer with either "large pressure difference," "small pressure difference" or "no pressure difference." The first question has been done for you.

- Points A and D (large pressure difference)

- Points A and B

- Points B and C

- Points B and E

- Points $\mathrm{E}$ and $\mathrm{F}$

- Points F and C

- Points $\mathrm{C}$ and D

\section{B. Voltage as an electric pressure difference}

Following the practical introduction to air pressure phenomena, the curriculum aims to connect the familiar with the new in order to scaffold a qualitative understanding of electric circuits. More specifically, the idea is to offer to students an intuitive explanation of voltage and potential by introducing the concept of "electric pressure" in analogy to "air pressure." For this purpose, students are told that electrons can move just as freely in metallic conductors such as copper as "air particles" can move in a bicycle tire. It is then argued that a wire, as long as it is not connected to a battery terminal, contains a "normal" amount of electrons that correspond to a "normal electric pressure." However, once the wires of an electric circuit are connected to a battery, the battery creates and maintains a polarity by pumping electrons from the wire connected

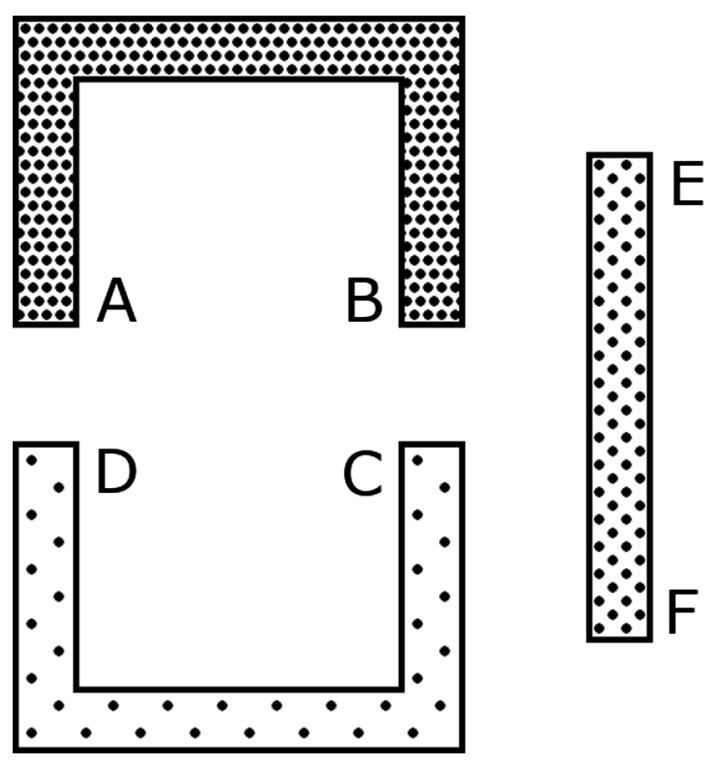

FIG. 3. A sample task to help students distinguish between air pressure and air pressure difference. 
with its positive terminal to the wire connected with its negative terminal. In analogy to the air pressure examples, it is then argued that this leads to a high electric pressure in the wire connected to the negative terminal and a low electric pressure in the wire connected to the positive terminal. Historically, the concept of electric pressure goes back to Volta and his investigations with electrometers around 1770. Based on these experiments, Volta concluded that positive mobile charges in conductors behaved like a compressible fluid with pressurelike properties [71].

In the curriculum, the battery itself is treated as a black box and students simply learn that it maintains a constant "electric pressure difference" across its terminals since it is aimed at lower secondary schools. Consequently, the "electromotive force" (EMF) is not introduced as part of this curriculum as students do usually not have an adequate background in chemistry yet and as even university students often struggle to understand the difference between these two concepts [72]. However, it is important to realize that the EMF is fundamentally different to potential differences, although these two physical quantities have the same numerical value if the battery is assumed to have no internal resistance. While the electromotive force is the work per unit charge done by a nonconservative force to create a potential difference (e.g., by chemical reactions in a battery or a changing magnetic field that leads to a nonconservative electric field), a potential difference refers to the work per unit charge done by a conservative electric force, e.g., when a charge moves through a resistor in an electric circuit.

The physical background of the concept of electric pressure lies in the role of surface charges in electric circuits since the conduction electrons are homogeneously distributed over the entire circuit. Any excess charges, according to Gauss's law, accumulate on the surface of the wire due to their mutual repulsion. Although the amount of surface charges is negligible compared to the amount of conduction electrons inside a wire, the charge separation caused by the battery therefore leads to a higher density of surface electrons in the wire connected to the negative terminal than in the wire connected to the positive terminal. From a physical perspective, it is this surface-charge gradient that makes the electric field that drives the current through the circuit. A more in-depth discussion of surface charges and their effect on the electric current can be found in Ref. [24].

As with any educational model used in school, it is important to be aware of its limitations. In the case of the air pressure analogy, teachers should therefore keep in mind that the current in electric circuits is not caused by a gradient of volume charges in the wire, but a gradient of charges on the surface of a conductor. This is particularly important as the air pressure analogy might otherwise lead to an erroneous conclusion as succinctly pointed out by
Mosca and De Jong [73] in their criticism of the CASTLE curriculum:

"The volume charge density throughout the interior of the wires and resistors is everywhere zero. In contrast, according to the compressible-fluid model it is the pressure gradient and not the electric field that drives the current. Furthermore, this pressure gradient results from a gradient in the charge-carrier number density - a volume density, not a surface density. [...] An erroneous conclusion associated with the compressible-fluid model is that it predicts the existence of an electric field within a charged conductor in electrostatic equilibrium. [...] In accordance with Gauss's law, any nonzero charge density is necessarily accompanied by an electrostatic field, and the presence of this field contradicts the widely accepted view that a conductor in electrostatic equilibrium is an equipotential."

As an introduction to the topic in middle schools, an analysis of electric circuits based on electric fields caused by a surface charge gradient, however, appears to be too abstract. The new curriculum therefore builds on a qualitative, low-abstraction prototype of electric potential that is based on a naïve understanding of air pressure by depicting surface charges as the cause of an electric pressure inside a wire. Voltage as potential difference can then be understood as an electric pressure difference across a resistor that is as much the cause for an electric current as air pressure differences are the cause for air flow [44]. The theoretical assumption behind this approach is that intuitive knowledge elements are not bound to a certain domain (e.g., air pressure phenomena) but can be productive in a wide range of contexts (e.g., electric circuits). According to diSessa, "[...] the implications of domain flexibility are critical for instructional design. We may or must explore widely if we want to build good intuitive bridges to scientific ideas" [48]. As a result of this assumed domain flexibility of intuitive knowledge, students' conceptual understanding in one domain can be facilitated by deliberately bringing intuitive ideas from another domain into prominence that would usually not be spontaneously evoked in that context by the students themselves. According to diSessa's concept of "out of the shadows learning," these intuitive out-ofdomain ideas have the potential to become the basis for a scientific understanding in the target domain, even if they are not part of the students' spontaneous interpretation of a certain context. In particular, these naïve ideas from a different domain may in fact be considered to be extremely useful by the students once evoked through instruction [48]. Applied to the curriculum presented in this paper, the idea is to take the students' intuitive understanding of air pressure out of the shadows by transferring it to electric circuits in order to build an intuitive bridge to a qualitative understanding of voltage in circuits. In other words, the curriculum aims to evoke students' intuitive ideas about air 
pressure when analyzing electric circuits, as these productive ideas would otherwise remain "in the shadows" [48]. As Ohm's p-prim is considered a "prototypical example of domain flexibility" by diSessa [48], the approach taken in this curriculum to reuse intuitive knowledge from the domain of air pressure in the domain of electric circuits in regard to Ohm's p-prim seems particularly promising.

As outlined before, students tend to analyze electric circuits from the perspective of the electric current that travels around the circuit element by element. It is worth pointing out that the underlying naïve causality of the students is usually devoid of agency in the sense that the electric current simply exists. An answer to the question why the electric current is considered a self-explanatory physical quantity by many students may lie in the p-prim that is typically activated when students deal with an electric circuit. Here, the "guiding" p-prim appears to have a high activation priority with regards to circuits prior to instruction. According to diSessa [66], the guiding p-prim is heavily influenced by visual considerations in the sense that "a determined path directly causes an object to move along it." Similar to diSessa's example of a "railroad car moving along a track," the guiding p-prim, when activated in the context of electricity, makes students think that the electric current simply flows along the electric circuit. Since the guiding p-prim is purely a description of observed phenomena, students are not looking for a cause (e.g., a potential difference) that is causing electric current. As a result, the activation of the guiding p-prim may rule out a causal interpretation of electric circuits [66]. An additional reason to avoid activating the guiding p-prim is that it may also lie at the root of what has been described as "sequential reasoning," as it implicitly suggests that the electric current sequentially flows through the circuit component by component.

Building on this, the instructional intent of the curriculum is to engage a deeper causality in students' thinking of electric circuits. However, since the guiding p-prim is not contingent on cause and effect, getting students to a causal interpretation of circuits is not an easy task. Although Ohm's p-prim, which students are already familiar with from the air pressure examples, relies on cause and effect, it is usually not activated in the context of electric circuits. Shifting students' activation priority from the guiding p-prim to Ohm's p-prim is therefore a key objective of the curriculum.

Building contingent reasoning based on Ohm's p-prim, however, requires students to reliably determine potential differences in various electric circuits. In the terminology of coordination classes, students must first learn to extract information about potential differences in electric circuits before making inferences using their inferential net from the air pressure examples based on Ohm's p-prim. The objective of the second unit of the curriculum is therefore to help students extract key information about electric

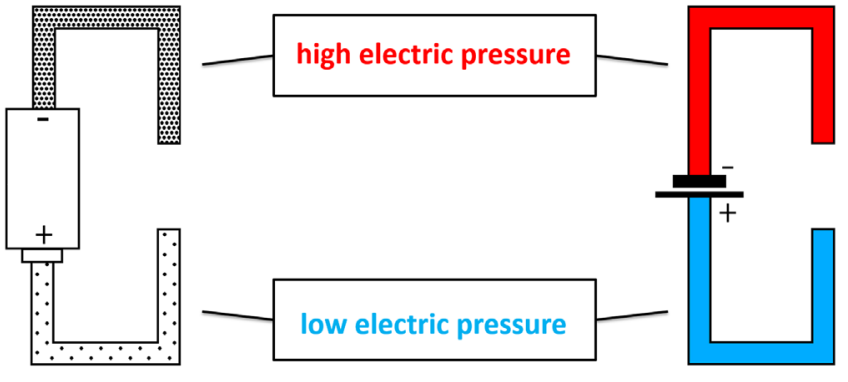

FIG. 4. The initial juxtaposition of the familiar particle model with color coding in an open circuit is intended to facilitate the students' transition from the idea of air pressure in pipes to electric pressure in wires.

pressure and electric pressure differences in circuits. An effective and yet simple way to facilitate the extraction of electric pressure in circuits and to increase the activation priority of Ohm's p-prim is presented by color coding the electric potential as shown in Fig. 4 (right).

In order to make the transition from air pressure to electric pressure easier for the students, the new color coding is introduced at the example of an open circuit, in which the electric pressure is initially also visualized using the familiar particle model [see Fig. 4 (left)]. In any further analysis of electric circuits, however, only color coding is used to represent the electric pressure for two reasons: From a practical point of view, the advantage of color coding is that it is much easier for the students to draw the electric pressure in wires using color pencils than it is to draw in countless dots. From a physical point of view, different dot densities before and after a resistor could easily make students believe that the electric current was consumed in a resistor. The choice of colors corresponds to the way in which values of different physical quantities are typically represented in everyday life. From weather charts, thermal imaging cameras or water taps, for example, students are used to the convention that high temperatures are shown in red and low temperatures in blue. Following this everyday convention, red is used for a high electric pressure while blue is used for a low electric pressure in the new curriculum. The color yellow is used to illustrate a normal electric pressure, e.g., if a wire is grounded or not connected to a battery yet. Students also learn how to measure electric pressure differences using a voltmeter. In order to visually distinguish the voltmeter from the rest of the circuit, the voltmeter is illustrated three dimensionally and its wires are not color coded as shown in Fig. 5. Arrows at the end of these wires are used to clearly indicate between which points of the circuit the electric pressure difference is measured.

The second unit concludes with a series of tasks in order to help students identify the electric pressure as the primary concept when analyzing electric circuits. In these tasks, the students are asked to color code the electric pressure in a number of different open circuits (see Fig. 6). Because of 


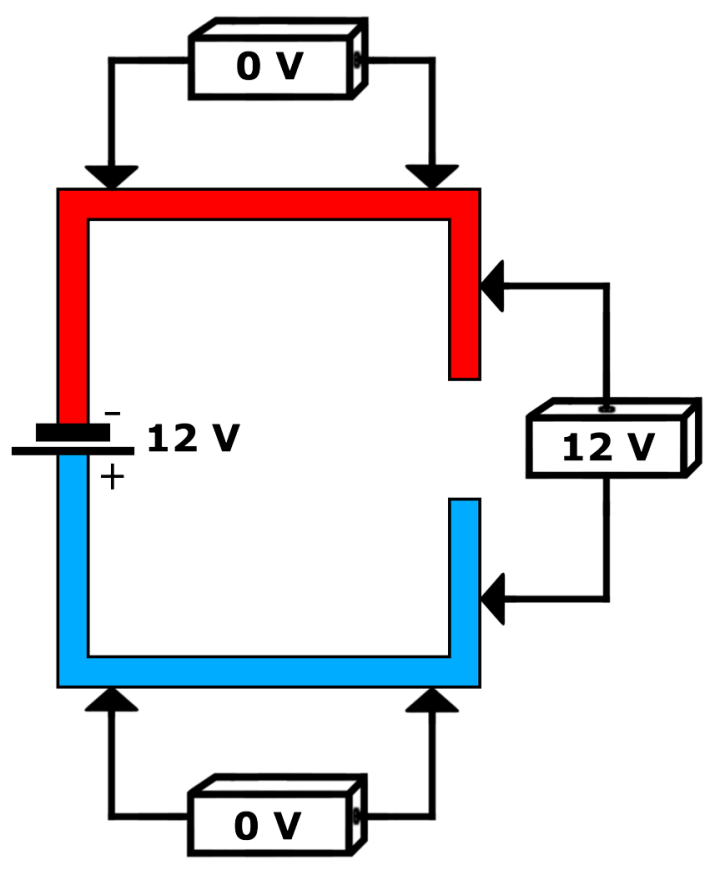

FIG. 5. Measuring of electric pressure differences with threedimensional voltmeters.

absence of an electric current, open circuits appear to be particularly suitable to reduce the activation priority of the guiding p-prim. Most importantly, the absence of an electric current allows students to focus their attention on the electric pressure. By coloring in the electric pressure in a wide range of open electric circuits, students learn to reliably extract the key information needed for making inferences about the electric current based on voltage and resistance. The systematic buildup of an inferential net based on the relation $I=V / R$ is the subject of the next unit of the curriculum.

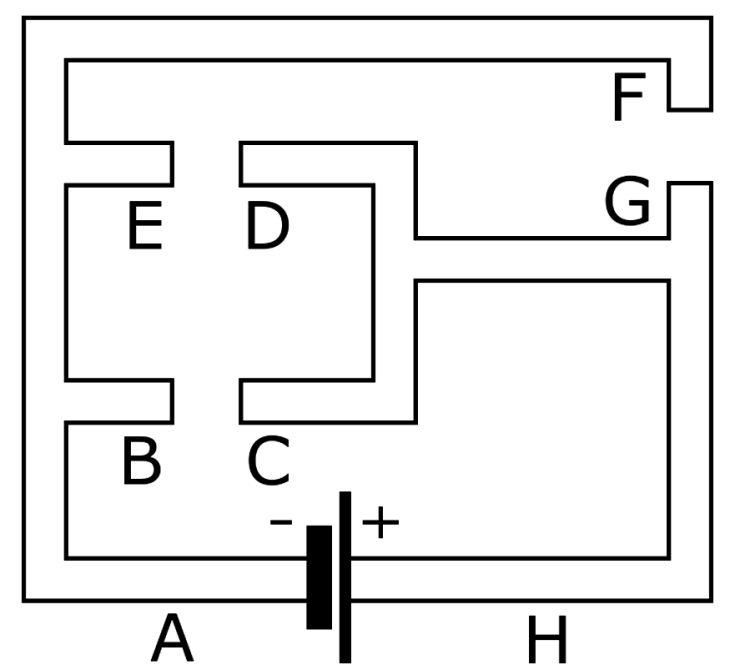

FIG. 6. Sample task designed to help students identify electric pressure differences in open circuits by using color coding.
In the one-on-one interviews, it was found that students were generally able to apply their intuitive understanding of air pressure to electric circuits using the idea of electric pressure. However, the one-on-one interviews also showed that students had problems with the term electric potential as it was considered quite abstract and has no linguistic relation to air pressure. We therefore decided to use the term electric pressure instead of electric potential in order to emphasize the analogy to air pressure in the curriculum. Accordingly, the term electric pressure difference is used synonymously for electric voltage to emphasize both the analogy to air pressure and the fact that voltage represents a difference in potential. The interviews also showed that the students believed that the electric pressure in the wires connected to the battery was dependent on their length. In particular, they expected the electric pressure in the wires to decrease with increasing length, as would be the case, for example, if pipes of different lengths were attached to a simple container with a high air pressure. The battery is therefore explicitly introduced as a special kind of pump that maintains a constant electric pressure difference regardless of the length of the wires connected to its terminals. In addition, tasks were included in the curriculum that specifically attempt to account for this intuitive inference from air pressure phenomena.

\section{An example from the curriculum}

A task designed to help students extract information on electric pressure and electric pressure differences in circuits refers to Fig. 6. The task is as follows:

Look at the circuit diagram with a $12 \mathrm{~V}$ battery.

(a) Color code the electric pressure in the wires using red for a high electric pressure and blue for a low electric pressure.

(b) What is the electric pressure difference-i.e., what is the potential difference (voltage) - between the different points marked with the following letters? Specify the potential difference (voltage) in volts. Voltage between points

- A and B

- $\mathrm{B}$ and $\mathrm{C}$

- $\mathrm{C}$ and $\mathrm{D}$

- $\mathrm{D}$ and $\mathrm{E}$

- $\mathrm{E}$ and $\mathrm{F}$

- $\mathrm{F}$ and $\mathrm{G}$

- $\mathrm{G}$ and $\mathrm{C}$

- $\mathrm{D}$ and $\mathrm{H}$

\section{Towards a qualitative understanding of circuits}

As a next step, the curriculum aims to equip students with an adequate understanding how they can infer information about the electric current from their observations of electric pressure. For this purpose, the students' inferential net from the air pressure examples is applied to electric circuits. Assuming that students can now reliably extract 
information about electric pressure differences, a simple circuit consisting of a battery and a light bulb is analyzed. Here, students are guided to the idea that an electric pressure difference across a light bulb leads to a flow of electric current through a light bulb just as an air pressure difference leads to an air flow through a piece of fabric. In analogy to the air pressure examples, it is then discussed that a resistor such as a light bulb impedes the flow of electrons in a similar way to a piece of fabric impeding air flow. In the same way that a thicker piece of fabric impedes the air flow more, light bulbs with a higher resistance are drawn with thicker lines in the curriculum (see Fig. 9). In line with diSessa's out of the shadows approach, the idea here is to build on students' prior intuitive understanding of air pressure phenomena in order to establish an adequate inferential net of $V, R$, and $I$ in electric circuits. In particular, students should achieve a qualitative understanding of the mutual relationship between $V, R$, and $I$ with the voltage causing the electric current and the resistance affecting it as shown in Fig. 7.

At this point, the students are also made aware of the apparent contradiction between the choice of colors for the positive and negative terminal in the curriculum and the convention commonly used in physics. The contradiction is attributed to the fact that scientists in the past did not know what the electric current was made of. For this reason, it was agreed that the electric current consisted of positively charged particles that would flow from the positive to the negative terminal. Accordingly, one assumed a "high electric pressure" at the positive terminal $(=$ red) and a "low electric pressure" at the negative pole (=blue). The students are then informed that this arbitrary convention is still used today and forms the basis for the direction of conventional current.

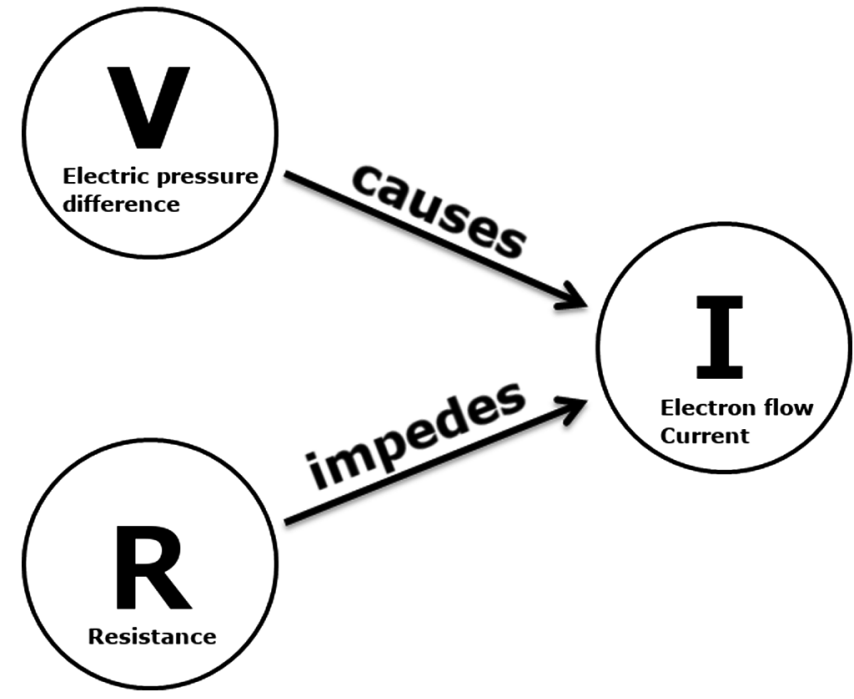

FIG. 7. A simple diagram visualizes the qualitative relationship between voltage $(V)$, resistance $(R)$, and current $(I)$.
The decision to use the electron flow rather than the conventional direction of current in the curriculum was taken primarily for two reasons: First, it is argued in the curriculum that a battery creates and maintains a polarity by pumping electrons from the wire connected with its positive terminal to the wire connected with its negative terminal. In analogy to the air pressure examples, it is then only reasonable to argue that the resulting electric pressure difference leads to a flow of electrons from the negative to the positive terminal. Second, the curriculum was specifically developed for secondary schools in Germany, where the focus of teaching is increasingly on the electron flow rather than the conventional direction of current. Consequently, in the curriculum, the arrows drawn in circuit diagrams illustrate the direction of the electron flow.

In order to help students develop a more fundamental understanding of resistance, a microscopic model of the conduction processes in conductors and resistors is introduced based on the Drude model. The idea is that in ideal conductors, the electrons almost never collide with the atomic cores as they are arranged very uniformly. In resistors, however, the electrons collide more frequently with the atomic cores, as they are not evenly arranged (see Fig. 8).

The one-on-one interviews revealed that some students struggled with the idea that a battery maintains a constant electric pressure difference across its terminals regardless of the resistance in a circuit. In particular, some students assumed that a higher resistance would also lead to a higher electron accumulation in the wire connected to the negative terminal in the same way that a larger road barrier would lead to a larger traffic jam. As a result, students expected the electric pressure difference to be greater across light bulbs with a higher resistance. It also turned out that some students initially believed that it was the electric pressure
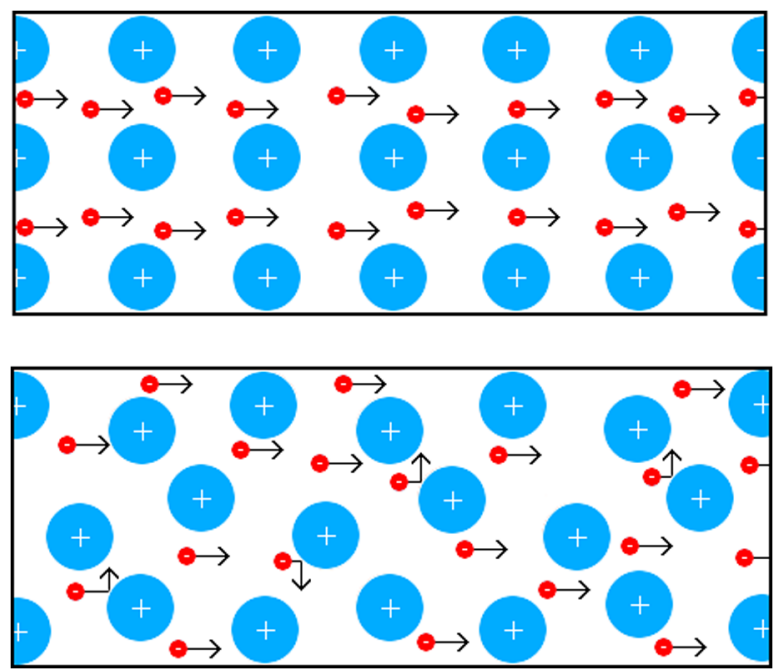

FIG. 8. A microscopic model of conductors (top) and resistors (bottom) based on the Drude model. 


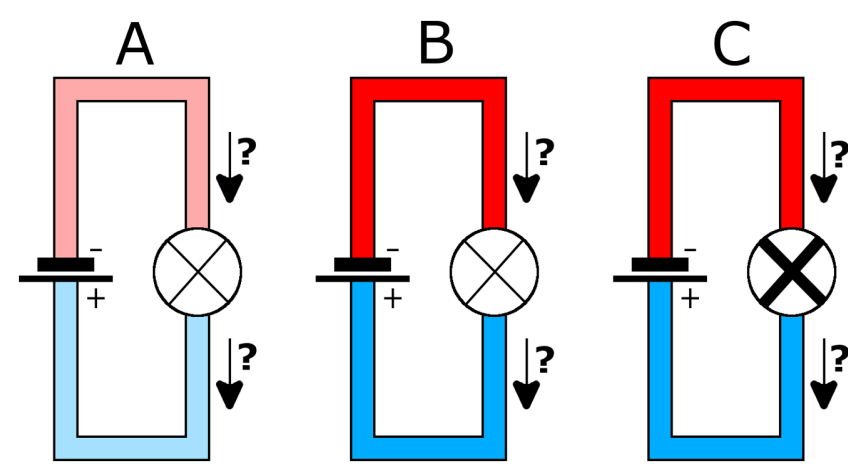

FIG. 9. Sample task to help students develop a qualitative understanding of how the electric current is dependent on electric pressure difference and resistance. The light bulb in circuit $\mathrm{C}$ has a higher resistance (illustrated by thicker lines). In this task, students are expected to identify that the flow of current is highest in circuit $\mathrm{B}$, but might be the same in circuits $\mathrm{A}$ and $\mathrm{C}$. The arrows only refer to the direction and not the magnitude of the electron flow.

that flows in circuits and not electrons. In order to account for these intuitive ideas, we have included tasks in the curriculum that address the fact that the battery maintains a constant electric pressure difference in the wires directly connected to its terminals regardless of the resistance of the light bulb (see Fig. 9). In addition, we asked teachers to emphasize that it is the electrons that flow in a circuit and not the electric pressure, e.g., by discussing conduction processes at a microscopic level as illustrated in Fig. 8. As some students in the one-on-one interviews also believed that the electric current was consumed by a light bulb, we decided to account for this intuitive but unproductive idea by drawing arrows before and after light bulbs in the circuit diagrams of the first units to visually emphasize that the current does not change as shown in Fig. 10.
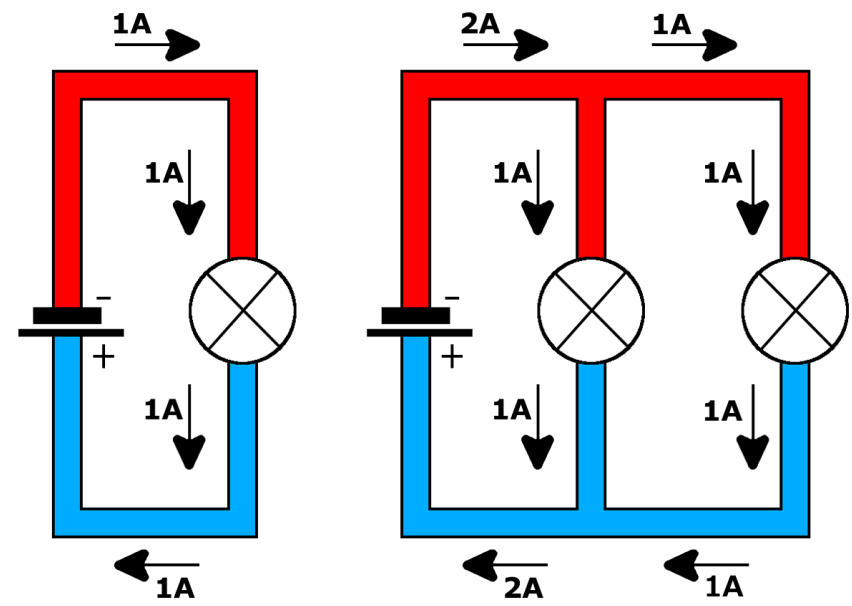

FIG. 10. In the case of an ideal battery, the electric pressure difference remains the same when a second light bulb is connected in parallel. Since the second bulb is identical to the first, the current leaving the battery doubles. The arrows refer to the direction of electron flow.

\section{An example from the curriculum}

A task to help students understand the relationship between voltage, current, and resistance is shown in Fig. 9. The task is as follows:

Arrange the following circuits A, B, and C according to the flow of current and explain your decision.

\section{Parallel circuits}

The decision to focus on parallel circuits once the students have developed a qualitative understanding of the mutual relationship between $V, R$, and $I$ in circuits with just a battery and a light bulb is based on the experiences gained in the one-on-one interviews conducted on a draft version of the curriculum. Here, some students had problems differentiating between current and potential. In particular, some students came to the erroneous conclusion that the current had to be the same in all wires with the same electric pressure. By measuring the current in the different branches of a parallel circuit, students can see that this is not the case. In order to help students distinguish between the concepts current and potential or potential difference, respectively, we furthermore encouraged teachers to measure the current with an analogue ammeter and voltage with a digital voltmeter in class. Also, some students in the one-on-one interviews considered the battery a source of constant current rather than constant voltage (cf. Ref. [6]) and tried to analyze the circuit from the perspective of the current that travels around the circuit element by element. Given the seemingly high activation priority of the guiding p-prim that we believe is at the heart of this problem, we asked teachers not to analyze the flow of current from one battery terminal to the other, as this would unintentionally further increase the activation priority of the guiding $\mathrm{p}$ prim. Applying their qualitative understanding of $V, R$, and $I$ to parallel circuits does not only help students recognize that the battery is a source of constant electric pressure difference, but also how important it is to consistently analyze circuits based on electric pressure differences. An analysis of series circuits would not only be less suitable to illustrate these aspects, but also more complex, since it requires the students to develop a dynamic mental model (see Sec. VII E).

In order to further refine the students' understanding of simple dc circuits, this unit focusses on the cause and effect relationship between voltage and current respectively in parallel circuits. The key objective here is to make voltage the students' primary concept when analyzing circuits by systematically increasing the activation priority of Ohm's p-prim in the context of parallel circuits. The first activity of the unit is therefore to look at a simple circuit with a light bulb, to which another identical light bulb is connected in parallel. Given that many students consider the battery to be a source of constant current, it is pointed out that an (ideal) battery in fact maintains a constant electric pressure difference. For this reason, the colors representing the electric 
pressure in the wires do not change regardless of the number of bulbs connected in parallel. Students are then asked to work out the electric current flowing through the two branches of the parallel circuit. Based on the given color coding, students first need to extract the information that the electric pressure difference is the same across both light bulbs (see Fig. 10). Knowing that the second light bulb is identical to the first, students then have to use their inferential net to work out that the electric current through both bulbs must be the same. It is then argued that the second light bulb draws an additional current that needs to be supplied by the battery. In order to avoid mathematical difficulties, only mathematically simple currents such as $1 \mathrm{~A}$ or $2 \mathrm{~A}$ are used in the curriculum. This is a deliberate design decision since the curriculum primarily aims to support students in developing a qualitative understanding of the relationship between current and voltage.

When analyzing parallel circuits, it is particularly important to decrease the activation priority of the guiding p-prim as it is devoid of agency and rather visual. A lack of an adequate coordination class therefore often reflects in naïve explanations that are more geometric than causal as students believe that the electric current divides into equal parts at each junction, regardless of the resistance of the light bulbs in the rest of the circuit (often referred to as "local reasoning"). Although it is technically not wrong to say that a current divides at each node with respect to a given parallel circuit, teachers should avoid such argumentation for two reasons: First, students are encouraged to analyze circuits from the point of view of the current, which would increase the activation priority of the guiding p-prim. Second, this reasoning implies that a battery is a source of a constant current that is divided between the different light bulbs in the parallel circuit. As can be seen from the example discussed above, this leads to wrong conclusions as soon as the number of bulbs connected in parallel changes. Teachers should therefore argue instead that the individual currents through the various light bulbs add up to a total current in the main branch, which needs to be supplied by the battery. It becomes evident that a correct understanding of circuits can only be achieved if voltage is the students' primary concept. The key objective of a number of tasks in this unit is therefore to systematically engage agency in students' thinking of parallel circuits by increasing the activation priority of Ohm's p-prim in the context of parallel circuits (see Fig. 11).

\section{An example from the curriculum}

A task to support students in determining the electric current in parallel circuits based on an analysis of electric pressure differences refers to Fig. 11. The task is as follows:

Look at the following circuit.

(a) Start by color coding the electric pressure in the wires.

(b) Explain how you know that the three light bulbs are connected in parallel.

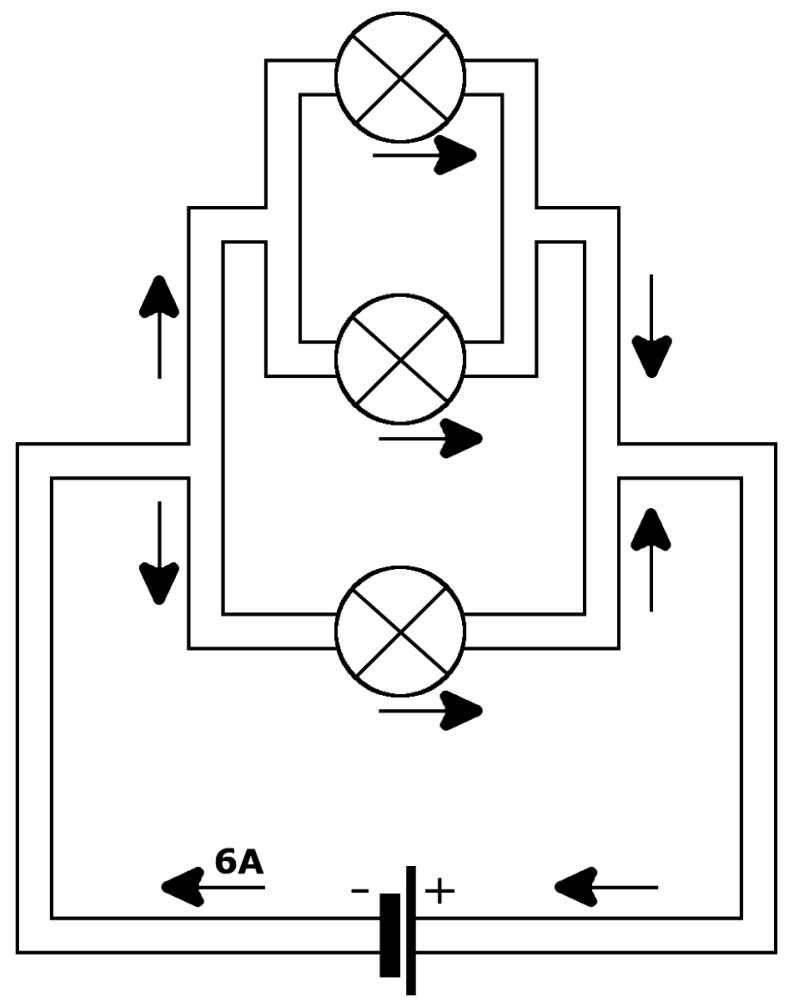

FIG. 11. A sample task to help students determine the electric current in a parallel circuit of three light bulbs based on an analysis of electric pressure differences. The objective of the task is to engage agency in students' thinking while decreasing the activation priority of the guiding p-prim. The arrows refer to the direction of electron flow.

(c) Determine the current in the various branches of the circuit and write it next to each arrow.

\section{E. Series circuits}

The electric pressure in all circuits discussed so far was static as all wires were attached to the battery terminal at one end. The analysis of series circuits, in contrast, requires the students to develop a dynamic mental model in order to determine the pressure magnitudes in wires that are not in direct contact with the battery. As the one-on-one interviews have shown that applying a dynamic mental model to series circuits can represent a challenge for some students, series circuits are only discussed after parallel circuits.

As the steady state, in which the voltage across all bulbs remains constant, is only achieved gradually over time, the analysis of series circuits is based on the so-called "initial state" and "transient state." In the initial state, all parts of the electric circuit still have a normal electric pressure as it has not been connected to the battery yet. The transient state refers to the very first moment when the electric circuit has been connected to the battery. Here, the battery has already created a high or low electric pressure in the wires directly touching its terminals. However, in the transient state it is assumed that the wires not directly connected to 


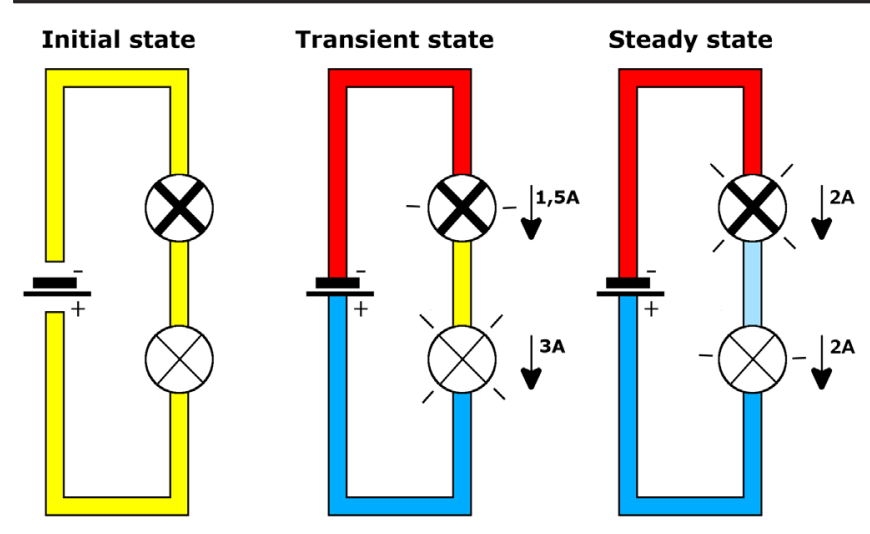

FIG. 12. Analysis of a series circuit using a dynamic mental model. Red stands for high electric pressure, blue for low electric pressure and yellow for normal electric pressure. Light blue stands for an electric pressure slightly lower than normal electric pressure. The upper light bulb with thicker lines has twice the resistance compared to the lower one. The arrows refer to the direction of electron flow.

the battery still have a normal electric pressure since no electrons have flowed through the light bulbs yet at that point. Based on the students' coordination class of how the electric current is dependent on electric pressure differences and resistance, students then need to work out the flow rate of electrons through the various bulbs.

In the series circuit shown in Fig. 12, for example, fewer electrons flow into the middle wire than out of it in the transient state, since the electric pressure difference across both bulbs is initially the same, but the top light bulb has a higher resistance than the bottom light bulb. As a result of these unequal flow rates, the electric pressure in the middle part of the wire decreases until the flow rate through both bulbs has equalized and the steady state has been reached. The slightly lower electric pressure compared to a normal electric pressure is visualized using a less intense blue here. Although thinking with dynamic models seems to pose some challenges to students, it provides them with an explanation within the model why voltage across a light bulb is dependent on its resistance in series circuits. In contrast, most other models ignore transient states and simply rely on rules to explain voltage in series circuits (e.g., "the bigger the resistance, the higher the voltage"). Figure 13 shows an example from the curriculum where students have to apply the idea of an initial, transient, and steady state to a series circuit with three identical light bulbs in order to work out that the electric pressure difference across all bulbs must be the same in the steady state.

\section{An example from the curriculum}

A task in which students need to use their dynamic model to explain voltage in series circuits refers to Fig. 13. The task is as follows:

Look at the following circuit.

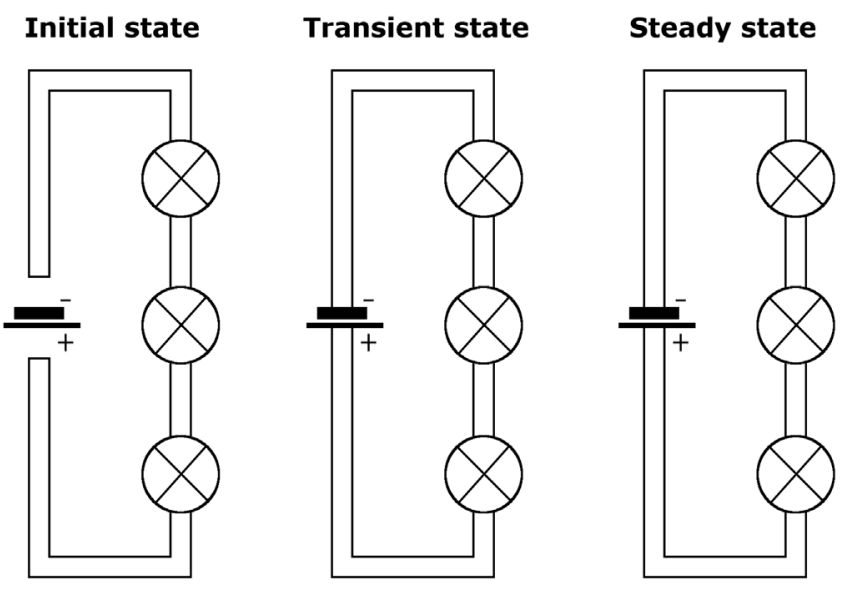

FIG. 13. Sample task in which the students use their dynamic model to qualitatively predict the voltage across two unequal light bulbs connected in series based on the change in electric pressure in the various parts of the circuit.

(a) Color code the electric pressure in the initial, transient, and steady state to show how it changes over time from the initial state to the steady state.

(b) Explain why the current through all three bulbs is the same in the steady state using the idea of electric pressure differences.

\section{F. Quantitative relationship}

As the curriculum primarily aims to help students develop a qualitative understanding of the mutual relationship between $V, R$, and $I$ with the voltage causing the electric current and the resistance affecting it, the quantitative relationship between $V, R$, and $I$ is only dealt with in the last unit of the curriculum. However, since physics is a quantitative science, this last step is important and should not be neglected.

As students are now hopefully able to extract information about potential difference in electric circuits and possess an adequate inferential net of how current is dependent on voltage and resistance, the final step in the curriculum is to transform their qualitative understanding into an understanding for the quantitative relationship $I=V / R$. For this purpose, the previously used diagram illustrating the qualitative relationship between $V, R$, and $I$ is juxtaposed to the equation $I=V / R$ as illustrated in Fig. 14. In accordance with a key demand by diSessa and Sherin [68], teachers are advised to put a lot of emphasis on a qualitative interpretation of this equation as a mathematical representation of the students' inferential net in subsequent examples to further strengthen their conceptual understanding of simple de circuits.

\section{REFLECTIONS ON DESIGN DECISIONS}

The design of the curriculum presented in this paper is based on key ideas of the knowledge in pieces perspective 
Qualitative relationship relationship

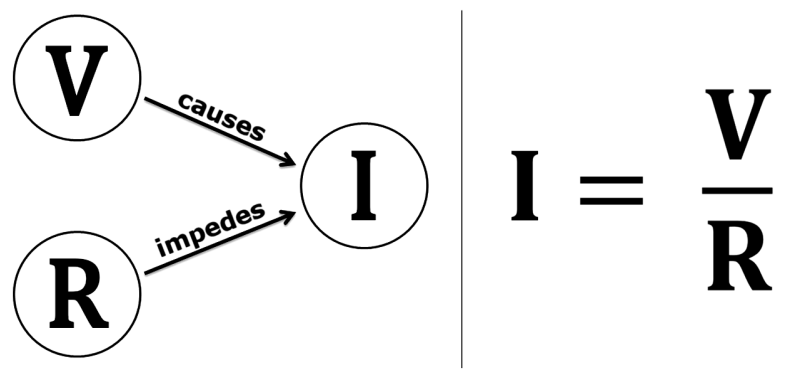

FIG. 14. Juxtaposition of the qualitative and quantitative relationship of voltage $(V)$, resistance $(R)$, and current $(I)$.

on learning. The strong influence of this perspective is reflected not only by the fact that the design of the curriculum is guided by key KiP concepts such as p-prims and coordination classes as outlined above, but more importantly by the fact that it considers naïve ideas as positive resources for learning. In particular, the curriculum builds on previously only loosely connected but productive p-prims, e.g., in the domain of air pressure, to systematically direct students' reasoning towards a scientific understanding of electric circuits. Using intuitive ideas from one domain to build a bridge to a scientific understanding in another domain, the approach taken in the curriculum represents a prototypical example for diSessa's out of the shadows learning. In particular, this approach is incommensurable with the framework theory as proposed by Vosniadou [63] or the ontological view proposed by Chi $[74,75]$ that do not see students' pre-instructional knowledge as a resource for learning. In regard to the latter, for example, diSessa [48] points out that the concept of domain flexibility " $[\ldots]$ violates the fundamental and widespread epistemological assumption that naïve ideas or theories are flatly false and for that very reason are in need of dismissal." The design decision to construct, transform, and reorganize students' intuitive knowledge elements into a coherent conceptual understanding in a step-by-step fashion is therefore in stark contrast to the assumption of the framework theory as well as the ontological view, which claim that students must be shielded from their naïve ideas as they are considered irretrievably wrong "by definition" [76]. Instead, conceptual change from Vosniadou's perspective, for example, can only happen if the whole "framework theory" is restructured as students' ideas are assumed to represent stable mental structures [63].

One strategy to achieve this would be to confront naïve ideas in the form of misconceptions rather than trying to build on intuitive knowledge elements to systematically scaffold learning. An example for such an approach that is more aligned with the ideas of Vosniadou represents the curriculum of McDermott and Shaffer [3] on introductory electricity. Explaining the design decisions behind their curriculum, they point out that it "[...] incorporates a number of specific strategies designed to address the [learning] difficulties [...]. Since many of these [misconceptions] are interdependent and mutually reinforcing, they cannot be isolated from one another and must be addressed together" [3]. As a result, they "[...] make frequent use of an instructional strategy in which the tendency to make a particular error is deliberately exposed [as] there is ample evidence that certain conceptual difficulties tend to persist unless specifically treated" [3]. Even if no direct reference is made to a framework theory, these quotes strongly suggest that key design decisions of their curriculum align with Vosniadou's perspective on conceptual change [63]. In particular, it becomes clear that McDermott and Shaffer [3] regard the pre-instructional knowledge of the students as an obstacle to learning and therefore take the view that these "misconceptions" must be "addressed," "exposed," and "specifically treated." As shown by this brief comparison of two approaches to teaching electric circuits, the theoretical perspective on learning and conceptual change can have a major impact on the design of curricula in physics education.

Furthermore, several general design principles for curriculum development can be derived from the work presented in this article that apply beyond the current study and beyond the specific topic of electric circuits. A key assumption of the KiP perspective is that students' naïve ideas in the form of p-prims can represent a positive resource for learning. Consequently, the learning of scientific concepts is understood as the transformation and reorganization of these "subconceptual" knowledge elements into coordination classes that represent scientific concepts in the KiP perspective. As these coordination classes consist of a perceptual (extraction) and inferential component (inferential net), they provide curriculum designers with a clear structure of scientific concepts. This structure can represent a powerful tool to guide the development of curricula based on KiP as illustrated in this paper. In particular, the idea to systematically address a coordination class' perceptual and inferential component one after the other in a curriculum to support the development of scientific concepts may prove to be valuable for researchers using the same theory of learning to design curricula for other fields in physics. As "shifting the means of seeing" is often considered "the core problem of conceptual change" [68], it may be particularly important to think of ways to help students reliably determine information on relevant physical quantities across a wide range of situations, e.g., by using visual cues. In the present study, the extraction of such information was facilitated by color coding the electric potential in circuits, but a similar design decision may facilitate conceptual understanding in other areas too.

The empirical findings regarding the effectiveness of the curriculum presented in this paper furthermore support the 
fundamental assumption of $\mathrm{KiP}$ that students' naïve ideas are not necessarily an obstacle to learning but can represent a valuable resource for curriculum designers. However, not every p-prim is necessary productive in every situation. In the case of electric circuits, for example, the guiding p-prim appears to have a high activation priority with regards to circuits and makes students think that the electric current simply flows along the electric circuit without a cause, i.e., the potential difference created by a battery. These findings have implications for PER researchers beyond electric circuits as they show that curriculum designers need to carefully explore students' intuitive ideas on a given topic in order to find out which knowledge elements can be built upon and reinforced as a resource for learning and which p-prims are best avoided in a curriculum. In other words: Rather than considering naïve ideas as misconceptions that need to be confronted in order to trigger conceptual change, PER researchers should focus on identifying productive p-prims in order to develop curricula that systematically build on the most promising of these knowledge elements to direct students' reasoning towards a scientific understanding while simultaneously avoiding unproductive p-prims.

Moreover, it was shown that students' intuitive understanding in one domain (air pressure) can be productive in scaffolding a scientific understanding in another domain (electric circuits). Curriculum designers subscribing to the KiP perspective but working on a different topic (e.g., mechanics or thermodynamics) may therefore want to explore if more intuitive out-of-domain ideas can also become the basis for a scientific understanding in their field of interest. As such, intuitive knowledge elements have their origin in a different domain to the target domain, PER researchers also need to find ways to systematically activate these p-prims in the target domain using appropriate cues. In the present study, for example, it was found that the term electric pressure is better suited to activate students' intuitive understanding of pressure in the target domain than electric potential. While researchers may draw on literature in some well-researched domains, less researched areas often require curriculum designers to first conduct pilot work to identify productive p-prims and appropriate cues (cf. Ref. [59]). In such cases, one-on-one interviews using the technique of probing acceptance (cf. Ref. [49]), as they were conducted on a draft version of the curriculum as part of this study, may represent a promising way to explore students' intuitive ideas as well as identify appropriate cues to activate them in the target domain.

\section{EMPIRICAL EVALUATION}

\section{A. Method and sample}

The curriculum presented in this paper was subject to an empirical evaluation in a quasi-experimental field study with $N=790$ students from Frankfurt am Main, Germany. In the state of Hesse, where this study was conducted, all children attend primary school for four years. After 4th grade, however, students attend different types of schools based on their academic performance in primary school. All students who took part in this study were attending a type of secondary school called "Gymnasium," which is aimed at higher ability students. As secondary schools in the state of Hesse are free to decide in which class "introductory electricity" is taught, about $25 \%$ of the students were in grade 7 while $75 \%$ were in grade 8 . However, it is important to emphasize that the students did not have any significant prior knowledge on electric circuits as this topic is covered for the first time in grade 7 or 8 . Furthermore, these students only had an intuitive understanding of air pressure from their everyday experiences with air mattresses or bicycle tires in the sense that compressed air is "under pressure" and tries to push itself out of a container. They likely had not developed a refined physical scalar concept of pressure as a state variable as the topic "pressure" is only dealt with in higher grades.

While the topic of electric circuits was new to the students, it is important to point out that the topic was not new to any of the teachers as all of the participating teachers had taught simple electric circuits before. Furthermore, they were all qualified and experienced physics teachers and participated in the study completely voluntarily. In the state of Hesse, teachers have a great deal of freedom in terms of content and methodology. The state standards only specify the contents to be taught (e.g., conductors, nonconductors, current, voltage, resistance, etc.), but do not specify which methods, models or analogies should be used in the classroom. In order to enable teachers to easily implement the ideas presented in this paper in their lessons, all teachers and students who participated in the empirical evaluation of the curriculum received a free textbook developed as part of the research project. Since teachers often use textbooks to guide their teaching in Germany [77], we believe this is a practical approach to overcome the often-lamented practice-research gap [54]. Furthermore, an advantage of this approach is that the results of the empirical evaluation reflect the impact the curriculum can have if widely adopted in schools.

The research question behind the study was to find out whether the curriculum presented in this paper leads to a better conceptual understanding than traditional approaches to teaching electric circuits. For this purpose, the study followed a pretest-postest-control-group design. The control group (CG) with $N=357$ students in grades 7 and 8 was taught the traditional way by 11 teachers for an average of 23.5 lessons $(\mathrm{SD}=11.9$ ) with a length of $45 \mathrm{~min}$. The slightly larger experimental group (EG) with $N=433$ students in grades 7 and 8 was taught according to the new curriculum by 14 teachers for an average of 24.3 lessons ( $\mathrm{SD}=9.8$ ) with a length of $45 \mathrm{~min}$. As both groups differ only slightly regarding the group size and the number of lessons taught and as the topic of electric circuits was 
covered in both groups for the first time, the CG and EG can be considered comparable.

\section{B. Test instrument}

The students' conceptual understanding was assessed with a valid and reliable two-tier multiple-choice test in both groups [78]. The original test instrument consists of 22 items and was developed in Vienna by an independent research group with no reference to the new curriculum. With its focus on students' conceptual understanding of current, resistance, as well as parallel and series circuits, the test instrument only assesses basic concepts that students are generally expected to learn in all schools in Germany and Austria at this level. Although various test items deal with the relationship between resistance and current, the original test instrument does not include a single item on voltage. In order to get at least some information on students' conceptual understanding of voltage, we added four items with a specific focus on voltage in simple electric circuits. The test instrument as it was used in the empirical evaluation of the curriculum can be found in Ref. [47]. Considering that 22 out of the 26 items of the testinstrument primarily deal with the concepts of current and resistance, it can be assumed that the test instrument is unbiased towards the new curriculum with its emphasis on voltage as a potential difference. The advantage of the twotier structure of the diagnostic multiple-choice test used here is that students not only have to give an answer to a question (first tier), but also an explanation (second tier). In the empirical evaluation, an item was only counted as correct if the answer and the explanation were given correctly. The highest achievable score in the test is therefore 26 points.

An advantage of the two-tier structure of the test is that it is not only possible to exclude false-positive answers (i.e., correct answers with an inadequate explanation), but to also gain a deeper insight into students' reasoning about electric circuits. The distractors in the multiple-choice test were selected on the basis of research into students' difficulties with electric circuits. These difficulties were repeatedly documented in a large number of studies on students' conceptual understanding of circuits in recent decades (e.g., that students, in some circuits, think that the current is consumed or that the battery is a constant current source) $[1,2,5,79]$. Figure 15 shows a sample item of the test instrument and its two tier structure. Students who choose $\mathrm{a} 2$ as their answer in the first tier and b3 in the second tier, for example, are interpreted to believe that the current consumption, in this particular circuit, is proportional to resistance. Whereas the selection of a3 in the first tier and b4 in the second tier is interpreted as the alternative conception that the battery is a source of constant current in this particular circuit. It is important to point out that in the KiP perspective, these incorrect patterns of response are not seen as the result of stable alternative conceptions that

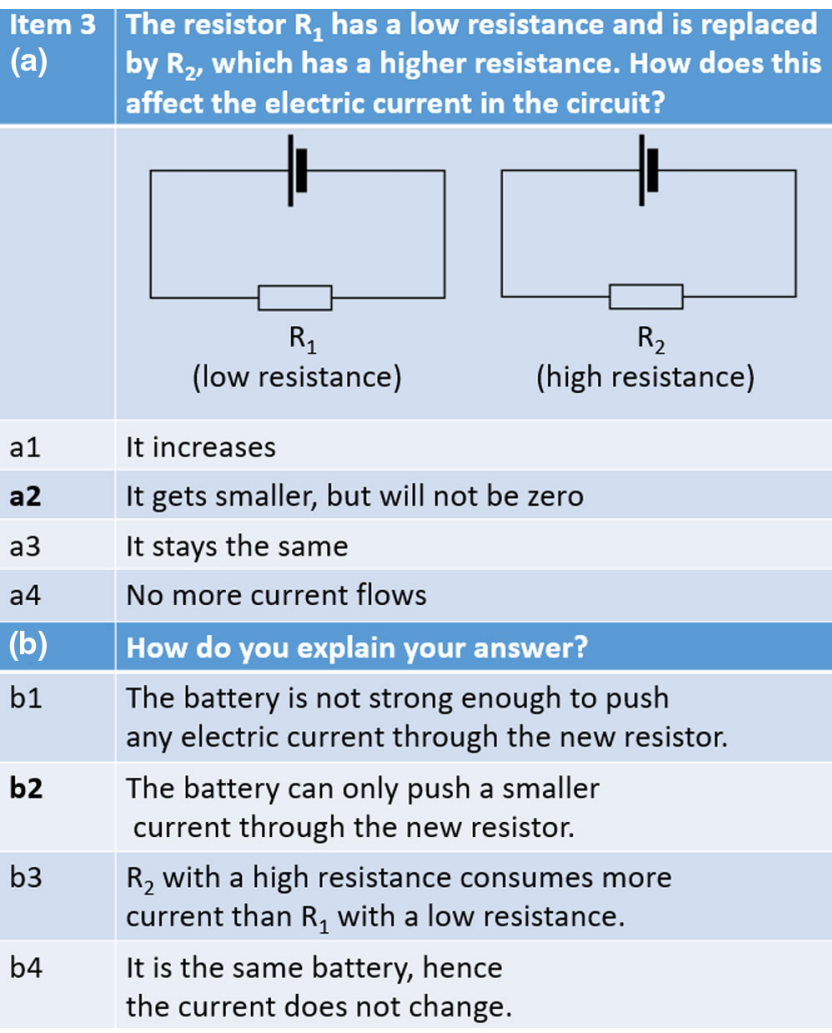

FIG. 15. A sample item from the test instrument illustrating the two-tier structure. The correct answer (a2) and explanation (b2) are printed in bold.

students consistently hold as they are part of a coherent naïve theory. Instead, it is assumed that students' responses to the questions in the test are spontaneously generated in an emergent manner based, among other things, on the activation priority of the underlying, highly context-sensitive p-prims that determine the students' interpretation of a circuit.

Traditionally, research on knowledge in pieces uses interviews as the objective is usually to examine the knowledge system of individual students in various contexts. While such interviews are ideally suited to get a detailed understanding of the students' knowledge systems, findings are difficult to generalize and the analysis can be time-consuming. The empirical evaluation of the curriculum, in contrast, is based on a multiple-choice test, which does not directly measure the structure of the students' knowledge systems. This departure from the existing methodological trend within the KiP literature was for two main reasons. First, even though the design of the curriculum was shaped by the KiP perspective, the purpose of the research project was not to contribute to the theory of KiP. Second, the aim of the present study was not to examine the knowledge system of a few students in depth, but to find out whether the new curriculum would lead to a better conceptual understanding of circuits if it were implemented on a large scale in Germany. Therefore, 
students' conceptual understanding of circuits was measured using a standardized, quantitative multiple-choice test rather than qualitative interviews. Although this multiple-choice test does not allow us to gain a deeper understanding of students' knowledge systems, its two-tier structure provides us with some information on students' reasoning about electric circuits as described above. In particular, this form of assessment allows us to come up with quantitative, generalizable results, which is an advantage over qualitative interviews with individual students given our research objective. However, it must be stressed that a multiple-choice test can never provide as detailed information on the knowledge structure of students as an interview, which can complicate the interpretation of the quantitative findings.

\section{Results of the empirical evaluation}

The analysis of the data was conducted using a multilevel analysis (MLA) as the students are "nested" in school classes and can therefore not be considered independent of each other. By accounting for this hierarchical data structure, a multilevel analysis provides an adequate estimate of the net effect of the treatment and its statistical uncertainty. Based on the empirical evaluation, the net effect of the new curriculum corresponds to 3.88 points (see Fig. 16), which is statistically a highly significant result and corresponds to a large effect size of $d=0.94$. Furthermore, a closer analysis of students' reasoning patterns using the two-tier structure of the test clearly shows that the new curriculum leads to a better conceptual understanding of circuits as students either have a comparable, or significantly lower probability to show typical incorrect patterns of response. In the KiP perspective, the lower proportion of students showing incorrect patterns of response in the EG can be interpreted as evidence that students' previously only loosely connected and highly context-sensitive p-prims have been successfully transformed and re-organized into a more coherent and stable mental structure in the EG. This allows students in the EG to more reliably read out conceptrelevant information and make correct inferences across a wide range of different circuits. Students' reasoning about electric circuits in the CG, however, tends to be shaped by unsuitable p-prims at the center of traditional approaches to teaching simple electric circuits. Another interpretation in the KiP perspective of the higher proportion of incorrect patterns of response in the $\mathrm{CG}$ is that their reasoning about electric circuits tends to be more disparate and unstable as slightly different visualizations of a physically identical circuit cue different p-prims, which may result in a completely different interpretation of the circuit.

However, there is only limited evidence to support these interpretations. In particular, these results could also be interpreted from a different theoretical perspective on learning. Based on the framework theory, for example, an alternative interpretation of the results is that the students

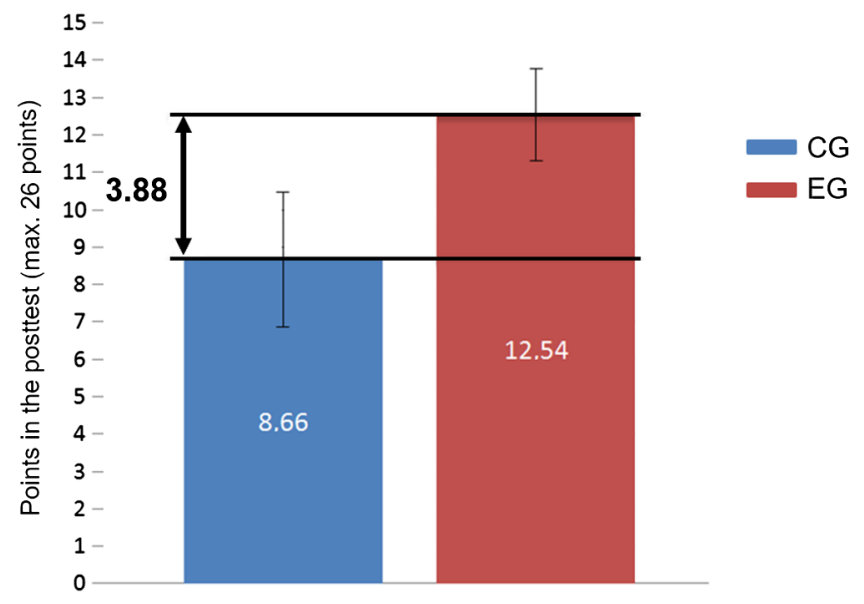

FIG. 16. Post-test results of the control group (CG) and experimental group (EG) with $95 \%$ confidence intervals. The pretest results were controlled for using hierarchical linear modeling. The statistically highly significant net effect of the treatment (3.88 points) is printed in bold. The highest achievable score in the test is 26 points.

taught according to the new curriculum have fewer stable alternative conceptions that are part of a coherent naïve theory such as the belief that current is "used up" in a circuit. The question, however, is to what extent such an interpretation is meaningful given that the design of the curriculum was shaped by the KiP perspective. As students were hence not specifically confronted with their old theories, the curriculum presented in this paper should not trigger conceptual change according to Vosniadou's framework theory. From this perspective, the fact that students nevertheless developed a better conceptual understanding of circuits represents an astonishing result.

Despite the significantly better conceptual understanding of the EG compared with the CG, the fact that students in the EG, on average, only achieved less than half of the highest achievable score in the post-test (12.54 out of 26 points), clearly shows that simple electric circuits are, unlike the name suggests, not a simple field of physics for most students. A more detailed discussion of the results of the empirical evaluation can be found in Ref. [47].

\section{Feedback from the teachers}

As this study represents a design-based research project, the research interest was not only whether students achieve a better conceptual understanding of simple dc circuits, but also where the teachers see the strengths and weaknesses of the new curriculum. Therefore, all 14 teachers who had taught according to the new curriculum were asked to give feedback on their practical experiences with it. Encouragingly, twelve out of these 14 teachers said they would teach according to the curriculum in future. Since the curriculum was also developed in the light of the often-lamented practice research gap [54], this is a 
promising result, as it shows that teachers have no fundamental objections against a broad implementation in the classroom. Furthermore, all 14 teachers agreed that the introduction of the concept of electric pressure difference was a good idea as it helped students to develop a better understanding of voltage. It was particularly emphasized that the air pressure analogy gave meaning to the concept of potential and potential difference and, in combination with color coding in circuit diagrams, helped students to develop a better understanding of the relationship between voltage and current in simple circuits.

However, considering the iterative character of designbased research and its commitment to sustained innovative development, it is of particular interest which aspects of the curriculum were viewed more critically by the teachers as such feedback provides a valuable insight for a redesign of the curriculum. One point of criticism was the choice of colors in the color coding. Although the chosen colors (red $=$ high pressure, blue $=$ low pressure) were described as intuitive, it was criticized that the color coding does not correspond to the convention in physics, according to which the positive terminal is red and the negative terminal is blue.

Furthermore, it was reported that some students thought of the battery as a device that supplies a constant current rather than a constant voltage, particularly when analyzing parallel circuits. As a result, they did not use voltage as their primary concept, but tried to analyze the electric circuit from the point of view of the current, which can lead to wrong conclusions as described in the introduction. One way to address this could be to promote the students' metacognition in order to help them to reflect on their own thinking when analyzing circuits. As part of a redesign, an illustration such as Fig. 17 could be included in the curriculum to guide students in the right direction when analyzing parallel circuits.

As many students had difficulties analyzing series circuits with "transient states," another point of criticism from the teachers was that the curriculum placed too much emphasis on the analysis of series circuits using a dynamic mental model. Rather than discussing electric pressure differences and their development in series circuits at length, the curriculum should focus instead on the relationship between total resistance and current. Interestingly, a similar decision was made by Psillos, Tiberghien, and Koumaras in their voltage-based curriculum, who opted to not treat the voltage distribution within circuits at all [22].

Furthermore, it is a matter of debate as to whether the introduction of the Drude model in lower secondary schools helps students to develop a better understanding of electric circuits. Given that Leniz, Zuza, and Guisasola [80] found that even university students have difficulties distinguishing between microlevel models (e.g., electrons

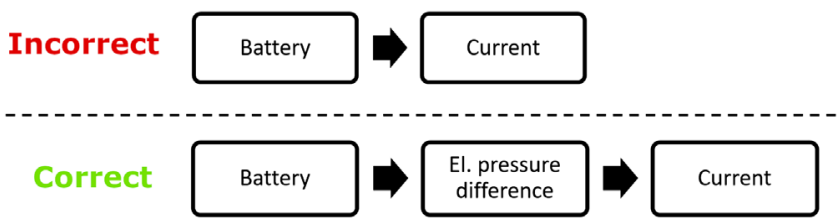

FIG. 17. An illustration to help students reflect on their own thinking when analyzing circuits. The incorrect way to analyze circuits is to think of the battery as a device that supplies a constant current and not a constant voltage (top). Instead, students must realize that the battery maintains an electric pressure difference, e.g., across a light bulb, that in turn leads to a current (bottom).

colliding with atomic cores) and macrolevel models (e.g., the air pressure analogy), an alternative would be to completely avoid a discussion of electrons at this introductory level. Instead, a future redesign of the curriculum could, for example, simply use the air pressure analogy to explain the conventional direction of current.

\section{CONCLUSION}

Effective reasoning about electric circuits requires a solid understanding of voltage. Based on diSessa's KiP perspective, the curriculum proposed in this paper systematically aims to guide students to a qualitative understanding of simple dc circuits. For this purpose, Ohm's law in the form $I=V / R$ is interpreted as a coordination class and its perceptual (extraction) and inferential component (inferential net) are addressed one after the other. Color coding the electric potential in a wide range of open circuits, students learn to reliably extract key information required for making inferences about the electric current based on voltage and resistance. As a next step, students' inferential net based on Ohm's p-prim is applied to simple electric circuits. In analogy to air pressure phenomena, in which an air pressure difference leads to an air flow, it is argued that voltage as an electric pressure difference leads to an electric current, e.g., through a light bulb. The theoretical assumption behind this approach is based on diSessa's concept of "out of the shadows learning," which, applied to the curriculum presented here, assumes that students' intuitive understanding of air pressure can become the basis for a qualitative understanding of simple circuits. By analyzing a wide range of circuits including parallel circuits, the curriculum aims to systematically engage agency in students' thinking of electric circuits by increasing the activation priority of Ohm's p-prim and decreasing the activation priority of the guiding p-prim that is seen as one of the reasons why the electric current often dominates students' thinking of electric circuits at the expense of potential differences. Towards the end of the curriculum, the equation $I=V / R$ is introduced as a mathematical representation of the students' qualitative inferential net of electric circuits. An empirical evaluation 
of the new curriculum with $N=790$ students in lower secondary schools has shown that the new curriculum leads to a significantly better conceptual understanding of electric circuits. Since the curriculum presented in this paper is currently only available in German in the form of a free textbook for schools, it is planned to publish an English version of it in future [81].

\section{ACKNOWLEDGMENTS}

The authors wish to thank Thomas Weatherby for his valuable comments on the draft of this paper. This work was supported by the Deutsche Telekom Foundation and the Vector Foundation. We also acknowledge support by the Open Access Publishing Fund of the University of Tübingen.
[1] D. M. Shipstone, C. v. Rhöneck, W. Jung, C. Kärrqvist, J.-J. Dupin, S. Johsua, and P. Licht, A study of students' understanding of electricity in five European countries, Int. J. Sci. Math. Educ. 10, 303 (1988).

[2] Aspects of Understanding Electricity-Proceedings of an International Workshop, edited by R. Duit, W. Jung, and C. v. Rhöneck (Schmidt \& Klaunig, Kiel, 1985).

[3] P. Shaffer and L. McDermott, Research as a guide for curriculum development: An example from introductory electricity. Part II: Design of instructional strategies, Am. J. Phys. 60, 1003 (1992).

[4] R. Duit, Bibliography - stcse students' and teachers' conceptions and science education (2009), http://archiv.ipn .uni-kiel.de/stcse/.

[5] L. McDermott and P. Shaffer, Research as a guide for curriculum development: An example from introductory electricity. Part I: Investigation of student understanding, Am. J. Phys. 60, 994 (1992).

[6] R. Cohen, B. Eylon, and U. Ganiel, Potential difference and current in simple electric circuits: A study of students' concepts, Am. J. Phys. 51, 407 (1983).

[7] D. M. Shipstone, A study of children's understanding of electricity in simple DC circuits, Eur. J. Psychol. Educ. 6, 185 (1984).

[8] J. Guisasola, International Handbook of Research in History, Philosophy and Science Teaching (Springer, Dordrecht, 2014) Chap. 5, pp. 129-156.

[9] L. Viennot, Reasoning in Physics. The Part of Common Sense (Kluwer Academic, Dordrecht, Netherlands, 2001).

[10] A. Tiberghien, Critical review of the research aimed at elucidating the sense that the notions of electric circuits have for students aged 8 to 20 years, in Research on Physics Education: Proceedings of the First International Workshop, edited by J.S. G. Delacote and A. Tiberghien (CNRS, Paris, 1983), pp. 109-123.

[11] C. v. Rhöneck, Vorstellungen vom elektrischen Stromkreis und zu den Begriffen Strom, Spannung und Widerstand, NiU-Physik 34, 10 (1986).

[12] U. Maichle, Schülervorstellungen zu Stromstärke und Spannung, NiU-Physik/Chemie 30, 383 (1982).

[13] D. P. Smith and P. van Kampen, Teaching electric circuits with multiple batteries: A qualitative approach, Phys. Rev. ST Phys. Educ. Res. 7, 020115 (2011).

[14] J. L. Closset, Sequential reasoning in electricity, in Research on Physics Education: Proceedings of the First
International Workshop, edited by J. S. G. Delacote and A. Tiberghien (CNRS, Paris, 1983), pp. 313-319.

[15] J. Möller and M. Jerusalem, Attributionsforschung in der Schule, Z. Pädagog. Psychol. 11, 151 (1997).

[16] L. Hoffmann, P. Häußler, and S. Peters-Haft, An den Interessen von Jungen und Mädchen orientierter Physikunterricht (IPN, Kiel, 1997).

[17] M. Heald, Electric fields and charges in elementary circuits, Am. J. Phys. 52, 522 (1984).

[18] W. R. Moreau, S. G. Ryan, S. J. Beuzenberg, and R. W. G. Syme, Charge density in circuits, Am. J. Phys. 53, 552 (1985).

[19] S. M. Stocklmayer and D. F. Treagust, A historical analysis of electric currents in textbooks: A century of influence on physics education, Sci. Educ. 3, 131 (1994).

[20] B. Eylon and U. Ganiel, Macro-micro relationships: The missing link between electrostatics and electrodynamics in students' reasoning, Int. J. Sci. Educ. 12, 79 (1990).

[21] H. Härtel, The electric voltage: What do students understand? What can be done to help for a better understanding?, in Aspects of Understanding ElectricityProceedings of an International Workshop, edited by $\mathrm{R}$. Duit, W. Jung, and C. v. Rhöneck (Schmidt \& Klaunig, Kiel, 1985).

[22] D. Psillos, A. Tiberghien, and P. Koumaras, Voltage presented as a primary concept in an introductory teaching sequence on dc circuits, Int. J. Sci. Educ. 10, 29 (1988).

[23] P. Licht, Teaching electrical energy, voltage and current: an alternative approach, Phys. Educ. 26, 272 (1991).

[24] R. W. Chabay and B. A. Sherwood, Matter \& Interactions (Wiley, Hoboken, NY, 2011).

[25] P. Sengupta and U. Wilensky, Learning electricity with Niels: Thinking with electrons and thinking in levels, Int. J. Comput. Math. Learn. 14, 21 (2009).

[26] A. A. diSessa, International Handbook of Research on Conceptual Change (Routledge, New York, 2013).

[27] E. Jochmann, O. Hermes, and P. Spies, Grundriss der Experimentalphysik und Elemente der Chemie sowie der Astronomie und mathematischen Geographie (Winkelmann \& Söhne, Berlin, 1914).

[28] C. Gleixner, Einleuchtende Elektrizitätslehre mit Potenzial, Ph.D. thesis, LMU München, 1998.

[29] C. v. Rhöneck, Wege zum Spannungsbegriff, NiU-Physik/ Chemie 36, 4 (1988). 
[30] H. Muckenfuß and A. Walz, Neue Wege im Elektrikunterricht (Aulis Deubner, Köln, 1997).

[31] U. Maichle, Representations of knowledge in basic electricity and its use for problem solving, in Proceedings of the International Workshop on Problems Concerning Students' Representation of Physics and Chemistry Knowledge, edited by W. Jung, H. Pfundt, and C. Rhöneck (Pädagogische Hochschule, Ludwigsburg, 1981), pp. 174-193.

[32] F. Herrmann and P. Schmälzle, Das elektrische Potential im Unterricht der Sekundarstufe I, MNU 37, 476 (1984).

[33] H. Härtel, Spannung und Oberflächenladungen - Was Wilhelm Weber schon vor mehr als 150 Jahren wusste, PdN-PidS 61, 25 (2012).

[34] J. J. Clement and M. S. Steinberg, Step-wise evolution of mental models of electric circuits: A "Learning-Aloud" case study, J. Learn. Sci. 11, 389 (2002).

[35] P. Sarantopoulos, G. Tsaparlis, and A. Strong, Analogies in chemistry teaching as a means of attainment of cognitive and affective objectives: A longitudinal study in a naturalistic setting, using analogies with a strong social content, Chem. Educ. Res. Pract. 5, 33 (2004).

[36] G. Ohm, Die Galvanische Kette, Mathematisch Bearbeitet (Riemann, Berlin, 1827).

[37] R. Duit, W. Roth, M. Komorek, and J. Wilbers, Fostering conceptual change by analogies-between Scylla and Charybdis, Learn. Instr. 11, 283 (2001).

[38] D. Gentner, Structure-mapping: A theoretical framework for analogy, Cogn. Sci. 7, 155 (1983).

[39] J. J. Clement and D. Brown, Creative Model Construction in Scientists and Students: The Role of Imagery, Analogy, and Mental Simulation (Springer, Dordrecht, 2008).

[40] A. Harrison and D. Treagust, Metaphor and Analogy in Science Education. Science \& Technology Education Library (Springer, Dordrecht, 2006).

[41] S. Kapon and A. diSessa, Reasoning through instructional analogies, Cognit. Instr. 30, 261 (2012).

[42] J.-P. Burde and T. Wilhelm, Moment mal... (22) Hilft die Wasserkreislaufanalogie?, PdN-Physik 65, 46 (2016).

[43] H. Schwedes, W.-G. Dudeck, and C. Seibel, Elektrizitätslehre mit Wassermodellen, PdN-Physik 44, 28 (1995).

[44] M. S. Steinberg and C. L. Wainwright, Using models to teach electricity-The CASTLE project, Phys. Teach. 31, 353 (1993).

[45] C. Waltner, S. Späth, D. Koller, and H. Wiesner, Einführung von stromstärke und spannung-ein unterrichtskonzept und ergebnisse einer vergleichsstudie, in Entwicklung naturwissenschaftlichen Denkens zwischen Phänomenen und Systematik. Jahrestagung der GDCP in Dresden 2009, Gesellschaft für Didaktik der Chemie und Physik No. 30, edited by D. Höttecke GDCP (Lit-Verlag, Münster, 2009), pp. 182-184.

[46] M.S. Steinberg, Electricity visualized-The CASTLE project. Student Manual (PASCO Scientific, Rosevill, CA, 2004).

[47] J.-P. Burde, Konzeption und Evaluation eines Unterrichtskonzepts zu einfachen Stromkreisen auf Basis des Elektronengasmodells (Logos-Verlag, Berlin, 2018).
[48] A. A. diSessa, Conceptual change in a microcosm: Comparative learning analysis of a learning event, Hum. Dev. 60, 1 (2017).

[49] G. J. Wiener, S. M. Schmeling, and M. Hopf, The technique of probing acceptance as a tool for teachers' professional development: A pck study, J. Res. Sci. Teach. 55, 849 (2018).

[50] W. Jung, Representations of knowledge in basic electricity and its use for problem solving, in Research in physics learning: Theoretical issues and empirical studies, edited by R. Duit, F. Goldberg, and H. Niedderer (IPN, Kiel, 1992), pp. 278-295.

[51] J.-P. Burde and T. Wilhelm, The electron gas model as an introduction to electricity in middle school science, in Science Education Research: Engaging Learners for a Sustainable Future, Proceedings of ESERA 2015, edited by J. Lavonen, K. Juuti, J. Lampiselkä, A. Uitto, and K. Hahl (University of Helsinki, Helsinki, Finland, 2016), pp. 26-36.

[52] W. A. Sandoval and P. Bell, Design-based research methods for studying learning in context: Introduction, Educ. Psychol. 39, 199 (2004).

[53] A. Collins, D. Joseph, and K. Bielaczyc, Design research: Theoretical and methodological issues, J. Learn. Sci. 13, 15 (2004).

[54] C. Bereiter, Design research for sustained innovation, Cognitive Studies, Bull. Japanese Cogn. Sci. Soc. 9, 321 (2002).

[55] A. L. Brown, Design experiments: Theoretical and methodological challenges in creating complex interventions in classroom settings, J. Learn. Sci. 2, 141 (1992).

[56] E. C. Lagemann, An Elusive Science: The Troubling History of Education Research (University of Chicago Press, Chicago, 2002).

[57] S. Barab and K. Squire, Design-based research: Putting a stake in the ground, J. Learn. Sci. 13, 1 (2004).

[58] A. Collins, Toward a design science of education, in New directions in educational technology, edited by E. Scanlon and T. O'Shea (Springer, New York, NY, 1992), pp. 15-22.

[59] P. Cobb, J. Confrey, A. diSessa, R. Lehrer, and L. Schauble, Design experiments in educational research, Educ. Res. 32, 9 (2003).

[60] D.-B. R. Collective, Design-based research: An emerging paradigm for educational inquiry, Educ. Res. 32, 5 (2003).

[61] A. A. diSessa, Constructivism in the Computer Age (Lawrence Erlbaum Publishers, Hillsdale, NJ, 1988).

[62] S. Vosniadou and W. F. Brewer, Mental models of the earth: A study of conceptual change in childhood, Cogn. Psychol. 24, 535 (1992).

[63] S. Vosniadou and I. Skopeliti, Conceptual change from the framework theory side of the fence, Sci. Educ. 23, 1427 (2014).

[64] Mental Models, edited by D. Gentner and A. L. Stevens (Lawrence Erlbaum Associates Inc, Hillsdale, NJ, 1983).

[65] M. McCloskey, Mental Models (Lawrence Erlbaum Associates Inc, Hillsdale, NJ, 1983).

[66] A. A. diSessa, Toward an epistemology of physics, Cognit. Instr. 10, 105 (1993). 
[67] A. A. diSessa, B. L. Sherin, and M. Levin, Knowledge and Interaction: A Synthetic Agenda for the Learning Sciences (Routledge, New York, 2016).

[68] A. A. diSessa and B. L. Sherin, What changes in conceptual change?, Int. J. Sci. Educ. 20, 1155 (1998).

[69] A. diSessa, Why conceptual ecology is a good idea, in Reconsidering Conceptual Change: Issues in Theory and Practice, edited by M. Limón and L. Mason (Springer, Dordrecht, 2002), pp. 28-60.

[70] A. A. diSessa, Invited Lectures from the 13th International Congress on Mathematical Education. ICME-13 Monographs (Springer, Cham, 2018).

[71] M. S. Steinberg, Inventing electric potential, Found. Sci. 13, 163 (2008).

[72] I. Garzón, M. D. Cock, K. Zuza, P. V. Kampen, and J. Guisasola, Probing university students' understanding of electromotive force in electricity, Am. J. Phys. 82, 72 (2014).

[73] E. Mosca and M. D. Jong, Implications of using the castle model, Phys. Teach. 31, 357 (1993).

[74] M. Chi, J. Slotta, and N. de Leeuw, From things to processes: A theory of conceptual change for learning science concepts, Learn. Instr. 4, 27 (1994).
[75] M. Chi, Commonsense conceptions of emergent processes: Why some misconceptions are robust, J. Learn. Sci. 14, 161 (2005).

[76] M. Chi, Two kinds and four sub-types of misconceived knowledge, ways to change it, and the learning outcomes, in International Handbook of Research on Conceptual Change, edited by S. Vosniadou (Routledge, New York, NY, 2013), pp. 49-70.

[77] T. Wilhelm, Konzeption und Evaluation eines Kinematik/ Dynamik-Lehrgangs zur Veränderung von Schülervorstellungen mit Hilfe dynamisch ikonischer Repräsentationen und graphischer Modellbildung (Logos, Berlin, 2005).

[78] H. Urban-Woldron and M. Hopf, Entwicklung eines Testinstruments zum Verständnis in der Elektrizitätslehre, ZfDN 18, 201 (2012).

[79] P. Engelhardt and R. Beichner, Students' understanding of direct current resistive electrical circuits, Am. J. Phys. 72, 98 (2004).

[80] A. Leniz, K. Zuza, and J. Guisasola, Students' reasoning when tackling electric field and potential in explanation of dc resistive circuits, Phys. Rev. Phys. Educ. Res. 13, 010128 (2017).

[81] www.einfache-elehre.de. 